\title{
Are ammonia emissions from field-applied slurry substantially over-estimated in European emission inventories?
}

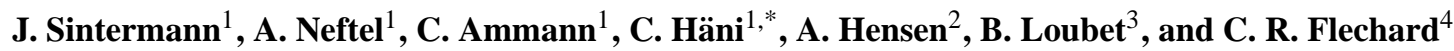 \\ ${ }^{1}$ Swiss Federal Research Station Agroscope Reckenholz-Tänikon ART - Air Pollution and Climate, Zürich, Switzerland \\ ${ }^{2}$ Energy research Centre of the Netherlands ECN, Petten, The Netherlands \\ ${ }^{3}$ Institut National de la Recherche Agronomique INRA, Thiverval-Grignon, France \\ ${ }^{4}$ Institut National de la Recherche Agronomique INRA, Agrocampus Ouest, UMR1069 SAS, Rennes, France \\ *now at: Bern University of Applied Sciences; School of Agricultural, Forest and Food Sciences; Zollikofen, Switzerland
}

Correspondence to: A. Neftel (albrecht.neftel@art.admin.ch)

Received: 25 July 2011 - Published in Biogeosciences Discuss.: 13 October 2011

Revised: 16 March 2012 - Accepted: 5 April 2012 - Published: 3 May 2012

\begin{abstract}
The EMEP/EEA guidebook 2009 for agricultural emission inventories reports an average ammonia $\left(\mathrm{NH}_{3}\right)$ emission factor $(\mathrm{EF})$ by volatilisation of $55 \%$ of the applied total ammoniacal nitrogen (TAN) content for cattle slurry, and $35 \%$ losses for pig slurry, irrespective of the type of surface or slurry characteristics such as dry matter content and $\mathrm{pH}$. In this review article, we compiled over 350 measurements of EFs published between 1991 and 2011. The standard slurry application technique during the early years of this period, when a large number of measurements were made, was spreading by splash plate, and as a result reference EFs given in many European inventories are predominantly based on this technique. However, slurry application practices have evolved since then, while there has also been a shift in measurement techniques and investigated plot sizes. We therefore classified the available measurements according to the flux measurement technique or measurement plot size and year of measurement. Medium size plots (usually circles between 20 to $50 \mathrm{~m}$ radius) generally yielded the highest EFs. The most commonly used measurement setups at this scale were based on the Integrated Horizontal Flux method (IHF or the ZINST method (a simplified IHF method)). Several empirical models were published in the years 1993 to 2003 predicting $\mathrm{NH}_{3} \mathrm{EFs}$ as a function of meteorology and slurry characteristics (Menzi et al., 1998; Søgaard et al., 2002). More recent measurements show substantially lower EFs which calls for new measurement series in order to validate the various measurement approaches against each other and to derive revised inputs for inclusion into emission inventories.
\end{abstract}

\section{Introduction}

Anthropogenic ammonia $\left(\mathrm{NH}_{3}\right)$ release to the atmosphere contributes to a large extent to the environmentally harmful effects of high nitrogen loads in terrestrial and aquatic ecosystems (Galloway et al., 2003; Erisman et al., 2007). Over $90 \%$ of these emissions in Europe have agricultural sources (Erisman et al., 2008; Reidy et al., 2008a; Hertel et al., 2011). $\mathrm{NH}_{3}$ emissions following the field application of organic fertilisers contribute roughly $30-50 \%$ to the total agricultural $\mathrm{NH}_{3}$ losses (Reidy et al., 2008b,a; Jarvis et al., 2011; Leip et al., 2011). The nitrogen, phosphorus and potassium content of organic manure make it an important nutrient resource for crop and forage production, and sustainable agriculture demands that losses to air and groundwater should be minimised. Consequently, abatement measures to reduce $\mathrm{NH}_{3}$ emissions from agriculture have a high priority. The evaluation of the efficiency of these measures depends on reliable emission inventories that must be based on reliable measurements under realistic field conditions.

In order to assess the variability and consistency of emission results reported in the literature, we compiled over 350 measurements from studies published between 1991 and 2011 that reported $\mathrm{NH}_{3}$ emission from agricultural fields after slurry application. We selected those studies for which the $\mathrm{NH}_{3}$ emission factor (EF), defined as the cumulative $\mathrm{NH}_{3}$ loss expressed as a percentage of the applied total ammoniacal nitrogen content (TAN) of the slurry, could be derived. The standard application technique, when the measurements started, was broad-spreading with splash plate. Figure 1a 
shows an overview of the reported EF values for splash plate application used in our analysis. They range from $4 \%$ to $100 \%$. Different management techniques, slurry properties (e.g. pH, TAN, dry matter content: DM) and varying environmental conditions (e.g. soil properties, history of management, etc.) are certainly responsible to some extent for the wide range of EF results, but potential biases in some of the used flux measurement methods may also account for a large fraction of the variability. The latter is very likely, given that $\mathrm{NH}_{3}$ volatilisation is a complex process and that $\mathrm{NH}_{3}$ flux measurements still face significant methodological challenges.

The EMEP/EEA guidebook 2009 (EEA, 2009, updated June 2010) for $\mathrm{NH}_{3}$ emission inventories indicates an average EF of $55 \%$ for cattle slurry and $35 \%$ for pig slurry for application with splash plate, which is considered as the reference case. These values are mainly based on the compilation of emission data of the Concerted Action (FAIR6-PL98-4057) that resulted in the ALFAM (Ammonia Loss from Field-applied Animal Manure) database (Søgaard et al., 2002). Major measuring programs were devoted to characterising the influence of meteorological variables and of slurry composition on the $\mathrm{NH}_{3}$ volatilisation using empirical models (Sommer and Olesen, 1991; Sommer et al., 1991; Menzi et al., 1998; Huijsmans et al., 2001; Søgaard et al., 2002; Huijsmans et al., 2003; Lim et al., 2007).

Over the last few years, low emission techniques such as trailing hose, trailing shoes, and slurry injection have been increasingly introduced, for which the associated $\mathrm{NH}_{3} \mathrm{EFs}$ are reduced in emission inventories by a certain percentage in relation to the reference case (splash plate). For trailing hose typically a reduction of $35 \%$, for trailing shoes of $64 \%$, and for slurry injection of $80 \%$ can be reached (Webb et al., 2010).

Most of the $\mathrm{NH}_{3}$ emission measurements published over the last 30 years have been carried out using wind tunnels (e.g. Lockyer, 1984) and the integrated horizontal flux (IHF) measurement technique (Wilson et al., 1983; Denmead, 1995). Wind tunnel measurements are generally performed on a small-scale plots $\left(<10 \mathrm{~m}^{2}\right)$, while the IHF is applied on medium-scale circular plots between $20 \mathrm{~m}$ and $50 \mathrm{~m}$ radius. These two techniques allow the measurement of (parallel or serial) replicates and are useful to investigate the relative influences of different drivers for the emission process, such as air temperature, wind speed, slurry DM content, etc. On the other hand, measurements at the full field scale ( $>0.5 \mathrm{ha}$ ) are relatively scarce. However, following technological advances in $\mathrm{NH}_{3}$ analysers, several field scale studies have appeared over the last few years (Berkhout et al., 2008; Gärtner et al., 2008; Loubet et al., 2010; Spirig et al., 2010; Sintermann et al., 2011a), and most of them seem to yield significantly lower EFs than the average/reference values suggested by the EEA guidebook.

In this paper, we review published EFs and flux measurement methods and analyse the data with the aim to disen-
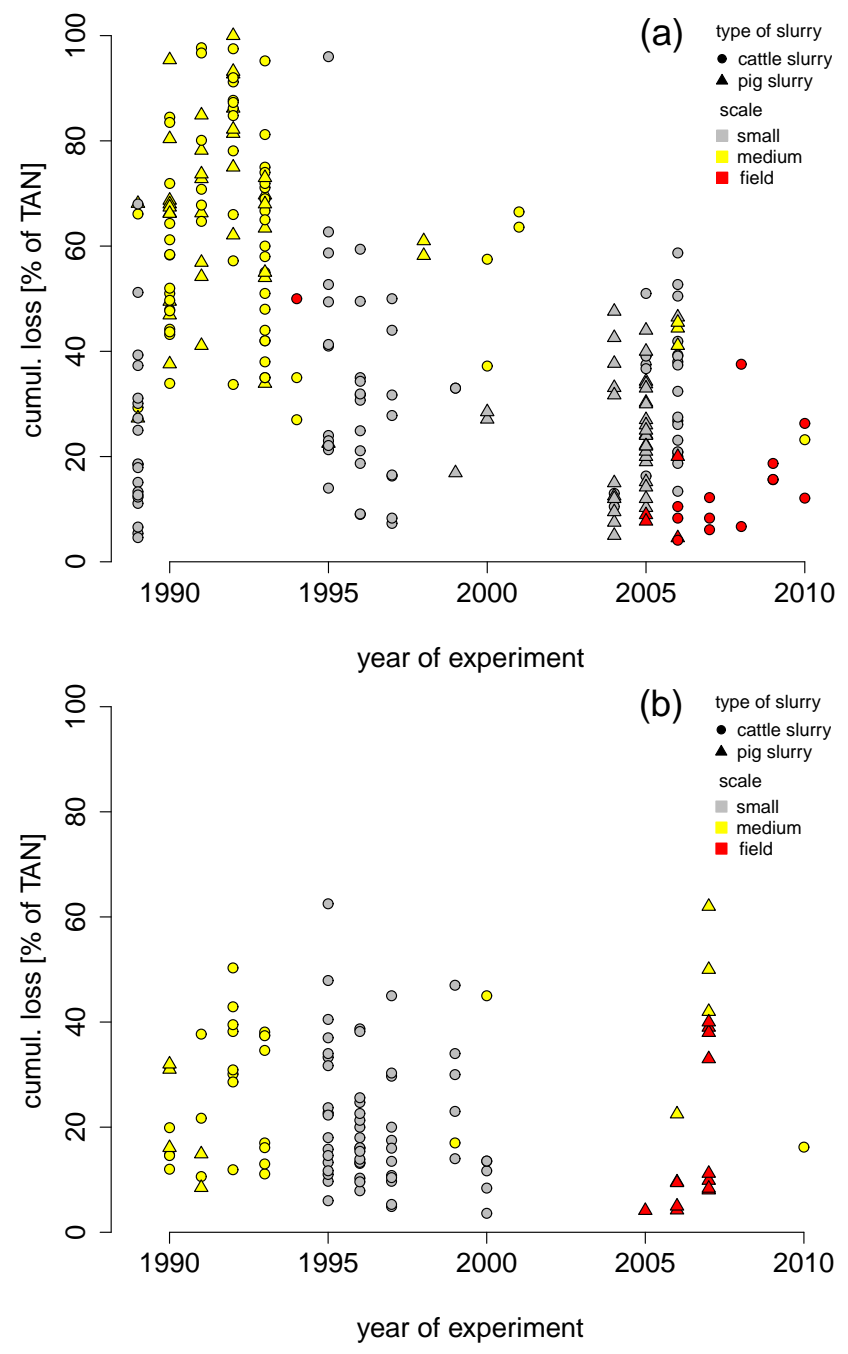

Fig. 1. Reported $\mathrm{NH}_{3}$ EFs for (a) splash plate application and (b) band (near-surface) spreading, plotted vs. the year of measurement. Circles show trials using cattle slurry and triangles represent pig slurry trials. A colour code is used for three classes of measurement plot scale (note that the resultes of Balsari et al. (2008) are excluded from this figure as no measurement year is reported).

tangle possible biases caused by analytical and methodological procedures, experimental setups and management influences. An important objective of the article is to critically examine the plausibility of published EFs and their suitability as data to underpin inventory methodologies for field $\mathrm{NH}_{3}$ emissions.

\section{Material and methods}

\subsection{Literature dataset}

The datasets used here were collected from studies published in peer-reviewed literature ( $93 \%$ of data) and in project reports or other grey literature ( $7 \%$ of data) between 1991 and 
2011. We selected reported experiments of $\mathrm{NH}_{3}$ emission measurements on agricultural fields after application of pig or cattle slurry. The minimum required information for inclusion in our dataset included the EF or the parameters needed to derive the $\mathrm{EF}$ (cumulative $\mathrm{NH}_{3}$ emission and the slurry application rate and TAN content), the slurry and spreading type, the $\mathrm{NH}_{3}$ emission measurement technique, the field type (grassland or arable), the year of the experiment, and a characterisation of the plot size. Table A1 provides an overview of the literature studies used in the analyses, sorted in alphabetical order. The various emission measurement methods that have been implemented in these studies are reviewed in the following section.

\subsection{Flux measurement approaches}

\subsubsection{Chamber techniques}

Placing a closed chamber on top of an emitting surface is, in principle, a simple way to determine exchange fluxes. Chambers can be run either in the static (non-steady state) or dynamic (steady state) modes. In a static chamber the flux is derived from the temporal change in the concentration within the chamber headspace. In a dynamic setup the air in the chamber headspace is ventilated and the flux is obtained from the concentration differences between the inlet and outlet air. The main advantages of chamber measurements are the conceptual simplicity, the possibility for many replicates and the limited costs. Disadvantages are the limited spatial representativeness of the measurements and the potential of inner chamber walls to alternately adsorb and release the sticky $\mathrm{NH}_{3}$ molecules. In most chamber applications published in the literature, $\mathrm{NH}_{3}$ concentrations were measured with either passive diffusion samplers (PDS) or impingers.

\subsubsection{Wind tunnel}

Wind tunnels are a special form of large dynamic chambers (Lockyer, 1984), in which a fan is used to suck air through "tunnels" formed by a translucent polyethylene roof covering a small area of about $1 \mathrm{~m}^{2}$ of slurry treated surface area. Within the wind tunnel the air flow and thus also the aerodynamic resistance is controlled; this can lead to a different emission flux compared with the flux level outside the wind tunnel, where the turbulence regime is different (Loubet et al., 1999b). Other difficulties with this method include the design and location of the sampling lines for the $\mathrm{NH}_{3}$ concentration measurements that can lead to varying recovery efficiencies (Loubet et al., 1999a), as well as low frequency turbulent motions in the tunnel which can be avoided by using properly designed inlets. Usually, impingers are used to measure the $\mathrm{NH}_{3}$ concentration in air at the inlet and outlet of the wind tunnel.

\subsubsection{Integrated horizontal flux approach}

The IHF method is a mass balance approach applied for the emission plume of a spatially limited source area. In order to be independent of wind direction, it is usually used with slurry spread onto circular plots (Denmead, 1983; Wilson et al., 1983; Denmead and Raupach, 1993). With a mast in the centre of the circle with radius $X_{\mathrm{R}}$, the horizontal (advection) flux $F$ of the upwind emitted $\mathrm{NH}_{3}$ is determined from the measured vertical $(z)$ profiles of concentration $(c)$ and horizontal wind speed $(u)$ :

$F_{\mathrm{IHF}}=\frac{1}{X_{\mathrm{R}}} \int_{z_{0}}^{z_{\max }} u(z)\left\{c(z)-c_{\text {bgd }}(z)\right\} \mathrm{d} z$,

where $c_{\text {bgd }}$ is the "background" concentration outside the emission plume, $z_{0}$ is the aerodynamic roughness length of the surface, and $z_{\max }$ is the maximum height of the emission plume (where the concentration equals $c_{\text {bgd }}$ ).

The IHF method is widely considered a very robust approach, as it is independent of surface characteristics and the state of atmospheric diffusion (Denmead, 2008; Laubach, 2010). In IHF studies over the last $20 \mathrm{yr}, \mathrm{NH}_{3}$ concentration profiles have mostly been measured using impingers (e.g. Huijsmans et al., 2001, 2003) or passive flux samplers (e.g. Leuning et al., 1985; Misselbrook et al., 2005).

\subsubsection{Aerodynamic gradient method}

The Aerodynamic Gradient Method (AGM) is based on the flux-gradient relationship in the constant flux layer. The flux $(F)$ is calculated from the friction velocity $\left(u_{*}\right)$ and the concentration scaling parameter $\left(c_{*}\right)$ as (e.g. Sutton et al., 1993):

$$
\begin{aligned}
F & =-u_{*} c_{*}, \\
c_{*} & =k \frac{\partial c}{\partial\left[\ln (\mathrm{z}-\mathrm{d})-\Psi_{\mathrm{H}}\right]},
\end{aligned}
$$

where $k$ is von Karman's constant $(k=0.4), z$ is the height above the ground, $d$ is the zero plane displacement, $c$ is the $\mathrm{NH}_{3}$ concentration and $\Psi_{\mathrm{H}}$ is the integrated stability correction function for scalar properties calculated from the Obukhov length $(L)$.

The parameters $u_{*}$ and $L$ can be obtained either from ultrasonic anemometry using eddy covariance (EC) or with AGM using temperature and wind speed profiles. This method requires a high-resolution $\mathrm{NH}_{3}$ analyser to accurately resolve vertical concentration gradients. Applied instruments include sampling units like wet annular denuders as in the AMANDA (Milford et al., 2009), GRAHAM (Wichink-Kruit et al., 2007), or GRAEGOR (Thomas et al., 2009) systems, as well as mini wet effluent denuders (Neftel et al., 1998; Herrmann et al., 2001; Milford et al., 2009; Loubet et al., 2010) or membrane diffusion samplers like AiRRmonia (Flechard et al., 2010), but also photo-acoustic 
analysers (de Vries et al., 1995; Pogany et al., 2010) have been used. The uncertainty of the AGM mainly depends on the precision of the analyser. Milford et al. (2009) found that the coefficient of variation of fluxes measured by several AMANDA systems side-by-side ranged from 20 to $30 \%$ for large fluxes and was larger than $76 \%$ for small fluxes. Moreover, in a spatially heterogeneous source/sink landscape the AGM is sensitive to advection errors (Loubet et al., 2001, 2009).

\subsubsection{Eddy covariance approach}

Following the EC method (Baldocchi et al., 1988; Dabberdt et al., 1993), the vertical flux of a trace gas at the sampling point is calculated as the covariance of the discrete time series (average product of the instantaneous deviations from the mean values) of the vertical wind $w(t)$ and concentration $c(t)$ over an averaging period $T_{\mathrm{a}}$ of typically 10 to $30 \mathrm{~min}$ over grassland. For closed path sampling systems the two time series have to be synchronised by a time lag $\left(\tau_{\text {del }}\right)$ in order to account for the delayed detection of the trace gas, mainly due to the tube transit time:

$$
\begin{aligned}
F & =\operatorname{cov}_{\mathrm{wc}}\left(\tau_{\mathrm{del}}\right) \\
& =\left(\frac{\Delta t}{T_{\mathrm{a}}}\right) \cdot \sum_{t=0}^{T_{\mathrm{a}}}(w(t)-\bar{w}) \cdot\left(c\left(t-\tau_{\mathrm{del}}\right)-\bar{c}\right),
\end{aligned}
$$

where $\Delta t=$ time difference between two recordings.

$\mathrm{NH}_{3}$ is a sticky gas species, i.e. the gas molecules can temporarily bind to solid and liquid surfaces inside sampling tubes and instruments (e.g. von Bobrutzki et al., 2010; Sintermann et al., 2011b). Closed path sampling of such sticky gas species produces a considerable amount of high-frequency attenuation that must be corrected for. This problem is a main limitation for the applicability of the EC approach for $\mathrm{NH}_{3}$ (Shaw et al., 1998; Whitehead et al., 2008; Brodeur et al., 2009). Ammann et al. (2006) presented an ogive-based empirical correction that accounts for signal loss due to insufficient time resolution of the analytical system, damping effects in the inlet line, and sensor separation. Assuming cospectral similarity, the attenuation factor is derived by comparison with the ogive of the sensible heat flux that is assumed to be unaffected by damping. Recently, Sintermann et al. $\left(2011 \mathrm{~b}\right.$, a) published EC-based $\mathrm{NH}_{3}$ flux measurements, successfully verified against established methods. They had to use a long inlet line heated to $150^{\circ} \mathrm{C}$ to reduce $\mathrm{NH}_{3}$ adsorption to the inner tube surface. The flux correction due to high-frequency damping was of the order of 20 to $40 \%$.

\subsection{Concentration-based dispersion modelling}

\subsubsection{Backward Lagrangian modelling}

$\mathrm{NH}_{3}$ emissions in field trials can also be determined with the help of dispersion models that relate a single (or multiple) concentration measurement within an emission plume to the emission rate of the corresponding (spatially limited) source area. The backward Langrangian stochastic model (bLS) by Flesch et al. $(1995,2004)$ is based on Lagrangian stochastic particle dispersion and uses Monin-Obukhov similarity theory to characterise turbulent transport. The model calculates an ensemble of particle trajectories, tracing the particles backward from the concentration sensor location to determine the resulting particle-ground intersections within or outside a given source area. The bLS approach has proven to be robust even with slightly perturbed turbulent conditions (Flesch et al., 2005). The model has been implemented in a freely available software called "WindTrax" (Thunder Beach Scientific, Halifax, Canada; www. thunderbeachscientific.com) that can be used via a graphical user interface (see review by Denmead, 2008).

A simplified version of the IHF method based on bLS modeling was published by Wilson et al. (1982). They used a 2-dimensional bLS model (a predecessor of the WindTrax model) and showed that the ratio of $\bar{u} \bar{c} / F$ for a homogeneous radial source density $F$ in a narrow height interval mainly depends on the surface roughness, and only marginally on atmospheric stability. Consequently, a reliable estimation of the source strength is possible by measuring the product of wind speed and concentration in the centre of a circle at one height (ZINST). This approach assumes a constant source strength over the manured circle and thus does not take into account the oasis effect (see Sect. 3.3.4).

\subsubsection{Eulerian inverse modelling}

The inversion method used in the bLS approach can also be used with Eulerian models. The FIDES inverse model (Loubet et al., 2001) is based on a semi-analytical solution of the advection-diffusion equation in the surface layer, initially developed by Godson (1958). In the FIDES model, the source is subdivided into grid cells each contributing to the observed concentration at a certain measurement height. A marked difference to the bLS model is the possibility to consider the surface as a concentration driven source as opposed to a flux driven source (Loubet et al., 2001, 2009, 2010).

\subsection{Empirical emission models}

\subsubsection{The ALFAM model}

In order to empirically describe cumulative $\mathrm{NH}_{3}$ emissions over time $t$ after slurry spreading, the ALFAM model (Søgaard et al., 2002) uses a Michaelis-Menten type equation:

$N(t)=N_{\max } \frac{t}{t+K_{\mathrm{m}}}$,

where $N(t)$ is the cumulative loss fraction of applied TAN, $N_{\max }$ the total time integrated loss fraction, and $K_{\mathrm{m}}$ the time after slurry spreading when half of the total emission has occurred. The instantaneous relative emission rate corresponds 
to the derivative $\mathrm{d} N / \mathrm{d} t$ of the above equation:

$\frac{\mathrm{d} N}{\mathrm{~d} t}=N_{\max } \frac{K_{\mathrm{m}}}{\left(t+K_{\mathrm{m}}\right)^{2}}$.

The equation implies a steady decrease of the emission intensity after the slurry application with an initial relative emission rate:

$$
\left.\frac{\mathrm{d} N}{\mathrm{~d} t}\right|_{t=0}=\frac{N_{\mathrm{max}}}{K_{\mathrm{m}}} .
$$

In the ALFAM model values of $N_{\max }$ and $K_{\mathrm{m}}$ have been statistically determined by a regression analysis of the compiled emission dataset. Key environmental and slurry composition factors influencing the total $\mathrm{NH}_{3}$ volatilisation were found to be wind speed and air temperature (respective increase enhancing $\mathrm{NH}_{3}$ loss), soil water content (dry soil yielding smaller loss than wet soil), slurry type (pig slurry yielding smaller loss than cattle slurry), slurry DM content (increase enhancing loss). $N(t)$ and $N_{\max }$ are defined in a dimensionless way as a fraction of applied TAN and are therefore implicitly linearly related to the slurry TAN content. The empirical model includes a negative deviation from this general linear $N_{\text {max }}$-TAN dependence $\left(-17 \%\right.$ per $1 \mathrm{~g} \mathrm{~N} \mathrm{~kg}^{-1}$ TAN increase).

\subsubsection{The Swiss empirical model}

Menzi et al. (1998) derived their empirical model from a combination of medium scale circular plot measurements using the ZINST approach and windtunnel measurements for typical Swiss conditions. The cumulative emission rate $E$ (in $\mathrm{kg} \mathrm{NH}_{3}-\mathrm{Nha}^{-1}$ ) is given as:

$$
E=(19.41 \cdot \mathrm{TAN}+1.1 \cdot \mathrm{SD}-9.51)(0.02 \cdot \mathrm{AR}+0.36),
$$

with $\mathrm{SD}=$ mean water vapour pressure saturation deficit (in mbar) and $\mathrm{AR}=$ application rate $\left(\right.$ in $\mathrm{m}^{3} \mathrm{ha}^{-1}$ ).

The empirical model was derived under the following conditions: liquid cattle slurry applied on grassland with splash plate, TAN content between 0.7 and $5 \mathrm{~g} \mathrm{~kg}^{-1}$, mean air temperature $0-25^{\circ} \mathrm{C}$, mean relative humidity $50-90 \%$ (SD range 1-11 mbar), and no rain. Contrary to the ALFAM model, no statistically significant dependence of $E$ on the DM content was observed (in a DM range of 2.8-5.4\%) in the underpinning measurements and therefore DM is not a model parameter.

\section{Data analysis and discussion}

We first checked the overall consistency of the dataset of collected EFs. Figure 1 shows the overview of the reported EFs separated for splash plate and band or near-surface spreading (trailing hoses and trailing shoes), plotted versus the year of measurement. The data are also split according to slurry type (cattle and pig) and measurement plot scale (small, medium, field). Since splash plate spreading was the standard application type during the last decades, there are more data available for this method.

The data in Fig. 1a show a high variability of reported EFs between a few percent up to $100 \%$, reflecting the large variability of conditions over the trials. The apparent decrease of measured EFs over the years is striking for splash plate data. Testing the difference in EFs for trials made before and after 2003 shows a significant difference $(p<0.001)$. All statistical tests were made using the (non-parametric) MannWhitney test, since the Shapiro-Wilk test indicated a nonnormal distribution of the datasets. The EFs for cattle and pig slurry are not significantly different, while EFs for band spreading (Fig. 1b) were generally lower than for splash plate and do not show a decrease after 2003.

Classifying $\mathrm{NH}_{3}$ loss rates for all splash plate trials according to experimental scale (Fig. 2a) yields a surprising result. Pair-wise differences in EFs between small scale, medium scale, and field scale were all found to be significant $(p<0.001)$. Medium size plots, generally circles between 20 and $50 \mathrm{~m}$ using either the IHF or the ZINST method, show the highest EFs, typically between 50 and $75 \%$. These values are considerably higher than the loss rates derived from field scale measurements using AGM and EC approaches.

The presented meta-analysis for slurry application with splash plate seems to imply that either (i) EFs for splash plate spreading have dropped substantially over the last $20 \mathrm{yr}$ (Fig. 1a), or (ii) different measurement techniques provide different emission results (Fig. 2), regardless of agronomical factors. As the EFs for splash plate application over medium size plots and determined by IHF or ZINST were systematically elevated, the main question is whether these deviations are caused by analytical differences (determination of the $\mathrm{NH}_{3}$ concentration), by systematic biases in the experimental setup, or by a true tendency for lower emissions over time e.g. due to changes in slurry characteristics and/or different meteorological conditions during the experiments (or a combination of all factors).

Figure 3 shows a comparison of measured EFs from field scale experiments in Switzerland performed by ART versus EFs as predicted by the ALFAM and Swiss empirical models presented in Sect. 2.4.2. Both models do exhibit a large offset as already noted by Spirig et al. (2010). Beside the large offset, the Swiss model is better correlated to the measurements than the ALFAM model, which to some extent is reasonable as the Swiss model was developed for Swiss conditions. The comparison with these two models underpins the discrepancy between field scale values and medium scale values and suggests that the difference cannot be explained with differences in meteorological and/or slurry characteristics.

In contrast to the results for splash plate application (Fig. 1a), the EFs for band spreading (near-surface application by trailing hose or trailing shoe) show no clear time trend 


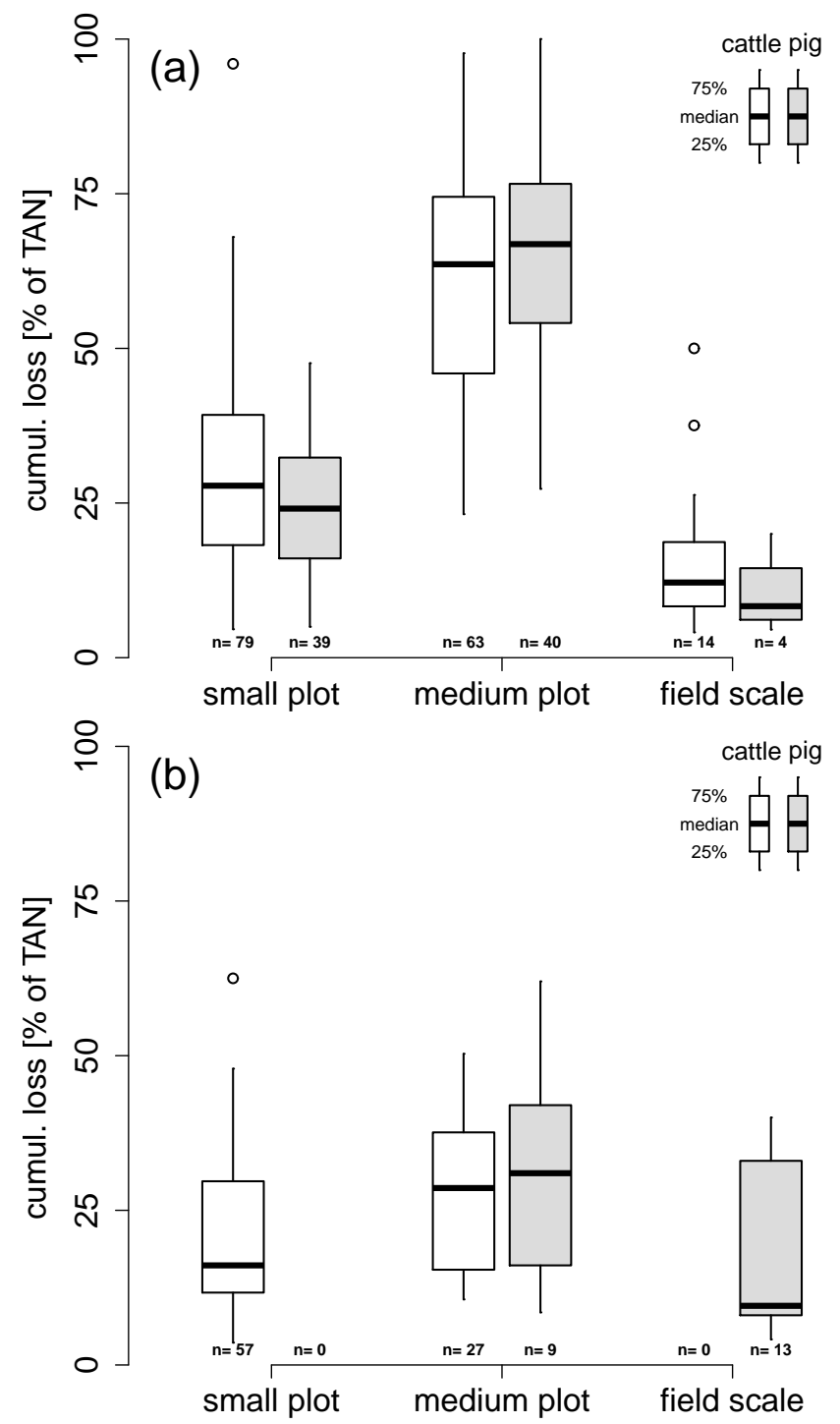

Fig. 2. Reported $\mathrm{NH}_{3}$ EFs for cattle and pig slurry depending on the measurement scale for (a) splash plate spreading and (b) band (near-surface) spreading; small plot scale: $<10 \mathrm{~m}^{2}$, medium plot scale: mostly circles with radius of 20 to $50 \mathrm{~m}$, field scale: typically $>5000 \mathrm{~m}^{2}$.

(Fig. 1b). This also suggests that changing slurry characteristics cannot explain the downward trend in Fig. 1a.

In the following we discuss possible biases of the first generation methods (predominantly small to medium plots with impingers or PDS) in view of the more recent analytical and methodological developments (mostly field scale with continuous analysers).

\subsection{Concentration measurement}

The accuracy of all emission flux measurements is directly related to the accuracy of the respective $\mathrm{NH}_{3}$ concentration measurements. If EFs from different studies are compared,

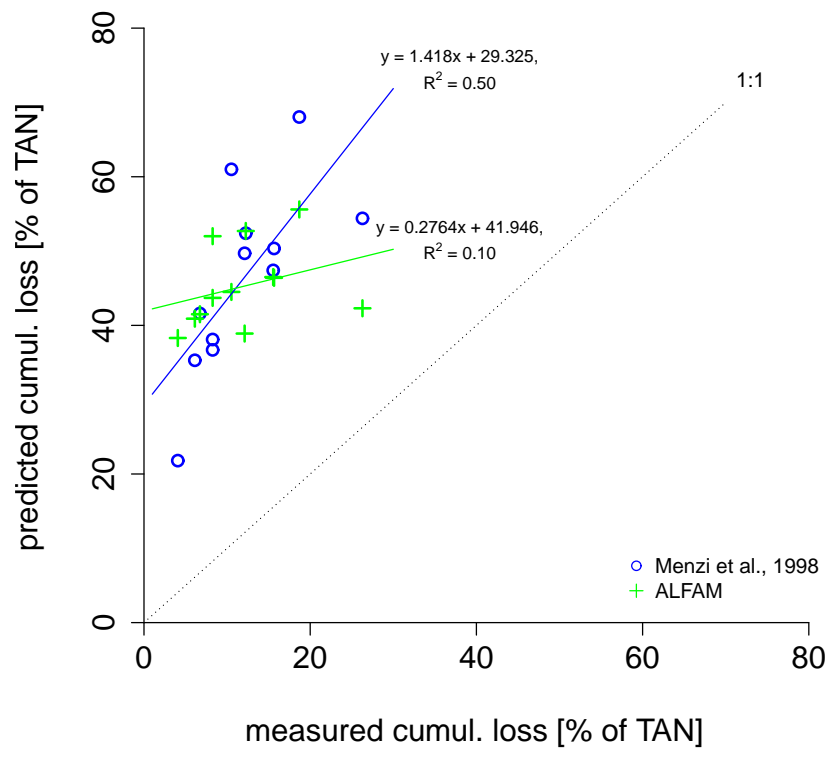

Fig. 3. Predicted vs. measured cumulated $\mathrm{NH}_{3}$ loss using the empirical models ALFAM (Søgaard et al., 2002) and that described by Menzi et al. (1998) for predictions; measured data come from a range of field-scale experiments (splash plate slurry distribution) carried out in Switzerland between 2006 and 2010 using AGM, bLS, and EC (Table A1: ART, Spirig et al., 2010; Sintermann et al., 2011a).

biases in $\mathrm{NH}_{3}$ concentration measurements will propagate to the reported EFs, making the comparison between studies flawed. Details concerning the $\mathrm{NH}_{3}$ concentration measurements are often missing in the publications, hinting that it is commonly and implicitly assumed that the measurements are well mastered and precise, but this may not be true of all studies.

In many applications the $\mathrm{NH}_{3}$ concentration measurements were done with impingers, an active sampling unit where the $\mathrm{NH}_{3}$ molecules in the sampling air are supposed to be scrubbed quantitatively in a liquid acidic trap. Doing so, an underestimation of the concentration can in principle only occur in case of an imperfect scrubbing efficiency. A second impinger behind the first one might be used to check this. A systematic overestimation of the concentration is only possible in case a contamination in the second impinger is used to correct the apparently low collection efficiency of the first impinger. Impingers are considered more accurate than PDS, as the latter cannot be easily checked for their collection efficiency and must be calibrated against a reference method. PDS can both under- or overestimate the true concentrations in case diffusion properties change. For example, Misselbrook et al. (2005) reported severe overestimation of PDS concentration compared to impingers.

Norman et al. (2009) presented an intercomparison of three instruments (PTR-MS, AiRRmonia, GRAEGOR) and also discussed several intercomparison studies. They 
concluded that deviations of 15 to $35 \%$ are common features of $\mathrm{NH}_{3}$ measurements. In a recent intercomparison experiment, von Bobrutzki et al. (2010) characterised eleven state-of-the-art instruments based on eight different detection methods under varying conditions. Inter-instrumental variations in measured $\mathrm{NH}_{3}$ concentrations up to $50 \%$ were found. Despite such measurement challenges, there is no evidence suggesting that the potential errors in the $\mathrm{NH}_{3}$ concentration measurements had a systematic influence on the different studies on $\mathrm{NH}_{3}$ emissions. Consequently, problems with concentration measurements can neither explain a potential bias in medium plot vs. small plot vs. large plot, nor a bias between the early 1990s and studies carried out later on.

\subsection{Limitations of chamber and wind tunnel methods}

\subsubsection{Potential biases in static chamber method}

For static enclosure measurements, linear regressions versus time of consecutive concentration measurements are often used to calculate the flux (Flechard et al., 2005). When applying a linear method, an underestimation of the flux easily occurs due to a decrease over time of the soil-air concentration gradient, and a non linear fit is required (Kroon et al., 2008). For sticky molecules like $\mathrm{NH}_{3}$ it is also possible that the concentration increase after closure is strongly dampened due to the sink activity of the chamber walls and thus even a non-linear fit can lead to a severe underestimation.

\subsubsection{Potential biases in wind tunnel method}

Loubet et al. (1999b,a) studied the wind-tunnels developed by Lockyer (1984) in detail. They showed that the tunnels tend to overestimate fluxes due to both an oasis effect (see Sect. 3.3.4) and a larger friction velocity inside the tunnel than outside, which is due to an increased wind speed gradient close to the surface. They also showed that the sampling design used to measure the outgoing air concentration could lead to under- or over estimation of the flux.

In the construction of the empirical ALFAM model it was distinguished whether the used emission data had been derived from wind tunnel or micrometeorological approaches (mainly IHF). It is striking that the ALFAM model predicts lower EFs for wind tunnel measurements (Søgaard et al., 2002). The authors argued that this was due to the lower wind speeds in the tunnels compared to typical ambient situations. This is in contradiction to the analysis by Loubet et al. $(1999 \mathrm{~b}, \mathrm{a})$ and must be regarded as an indication of a systematic overestimation of the other (IHF derived) data that determined the ALFAM model.

\subsection{Limitations and potential biases of horizontal flux methods}

\subsubsection{Turbulent horizontal flux contribution}

It is common practice to approximate the IHF integral by a discrete sum using the average wind speed and concentration data $\bar{u}_{i}$ and $\bar{c}_{i}$ measured at several height levels $i$ :

$F \cong \frac{1}{X_{\mathrm{R}}} \sum_{1}^{n}\left(\overline{u_{i}} \overline{c_{i}}\right) \Delta z_{i}$

with $n$ denoting the number of measurement points, $X_{\mathrm{R}}$ the radius of the circular plot, and $\Delta z_{i}$ the height of layer $i$. The measurements are usually averaged over the sampling time of the concentration detection, typically about $1 \mathrm{~h}$. However, from turbulence theory it is known (Denmead et al., 1977; Denmead, 1995) that:

$\overline{u c}=\bar{u} \bar{c}+\overline{u^{\prime} c^{\prime}}$,

with $u^{\prime}$ and $c^{\prime}$ denoting the instantaneous deviations of $u$ and $c$ from their respective mean value.

The first term on the right hand side of Eq. (9) represents the transport due to advection, and the second term that due to horizontal turbulent diffusion (Denmead, 1983). Raupach and Legg (1984) already reported on the need to account for this turbulent backflow term $\overline{u^{\prime} c^{\prime}}$, which was further discussed by Denmead (1995). Only if $u^{\prime}$ and $c^{\prime}$ were not correlated, $\overline{u^{\prime} c^{\prime}}$ would vanish. Since turbulence always leads to a similar vertical transport of horizontal momentum transported towards the surface (represented by $u$ ) and trace gas concentrations, there is a correlation between $c^{\prime}$ and $u^{\prime}$. In case of an emission the sign of the trace gas flux is opposite to the momentum flux and consequently is negative (Leuning et al., 1985; Wilson and Shum, 1992). EC measurements with high temporal resolution can illustrate this effect. In Fig. $4, c_{\mathrm{NH}_{3}}^{\prime}$ is plotted vs. $u^{\prime}$ for a $10 \mathrm{~min}$ raw dataset, recorded $1 \mathrm{~m}$ above ground downwind of an arable field fertilised with slurry (see Sintermann et al., 2011a). The $\mathrm{NH}_{3}$ flux was around $7000 \mathrm{ng} \mathrm{m}^{-2} \mathrm{~s}^{-1}$, a typical flux following slurry application. $c^{\prime}$ is anti-correlated to $u^{\prime}$ in a non-linear way with highest positive deviations of the concentration associated to lowest horizontal wind speeds. Not correcting for the $\overline{u^{\prime} c^{\prime}}$ term will lead to a systematic overestimation of the reported flux, provided $u c$ is not measured with a sampler that collects $\mathrm{NH}_{3}$ proportional to $u$ (see Leuning et al., 1985; Schjoerring et al., 1992). The $\overline{u^{\prime} c^{\prime}}$ correction can be somewhere between $5 \%$ and $20 \%$ depending on stability. Time integrated measurements by definition do not provide the information to quantify the correction and values derived from model calculation have to be applied.

\subsubsection{Wind speed measurements}

A potential problem might arise in case wind speeds are measured with cup anemometers that show an imperfect 


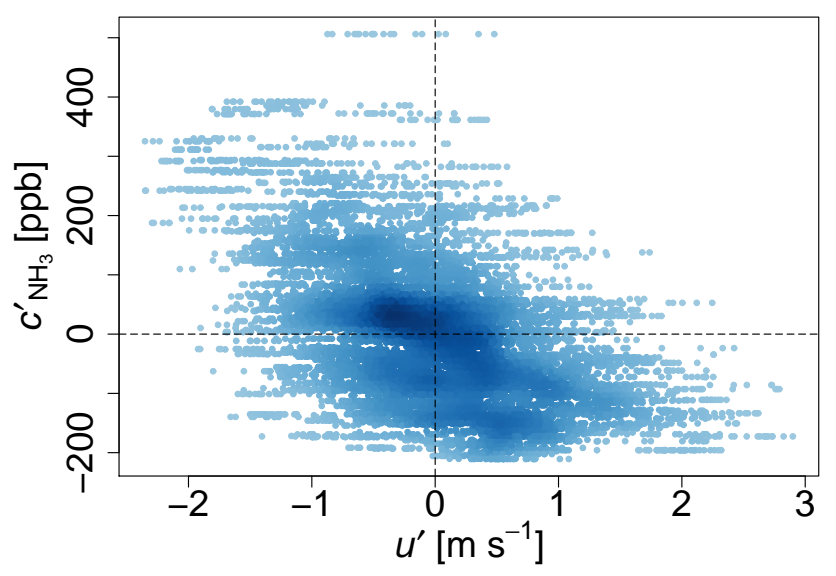

Fig. 4. One $10 \mathrm{~min}$ interval of $c^{\prime}$ vs. $u^{\prime}$ measured by EC using CIMS following slurry spreading (splash plate) on arable land (Sintermann et al., 2011a), 4 August 2009.

behaviour at low winds. On the one hand, cup anemometers need a certain minimum wind speed before they begin to move. The stalling speed is instrument-dependent and ranges from 0.2 to $1 \mathrm{~m} \mathrm{~s}^{-1}$. Therefore, without specific calibration they underestimate the wind speed in this range. However, the instruments are often calibrated in a wind tunnel (with laminar air flow) to correct for this effect. On the other hand, in the real atmosphere with fluctuating wind speed due to turbulence, cup anemometers show an "overspeeding" effect (i.e. their response to increasing wind speed is faster than to decreasing wind speed leading to an overestimation of the average value) at lower wind speeds (Rotach, 1991; Kristensen et al., 2003). The lowest measuring points carrying a large fraction of the horizontal fluxes are especially affected by this overestimation. Only with information about the performance and possible correction of the wind speed measurements is it possible to assess this effect quantitatively.

\subsubsection{Limited measurement height}

Part of the emitted flux might pass above the mast if it is lower than the internal boundary layer height $\left(z_{\max }\right)$ of the manured plot. A check on this is possible when background tower measurements are available to determining the background concentration level. If the $\mathrm{NH}_{3}$ concentration measured (at the circle centre) at the highest level is at the background concentration, the entire internal boundary is seen by the measurement. However, while this check is normally carried out for the first measurements taking place after fertilisation (with 1-2-4 h intervals), for the last intervals which can be 1-2 days long, the wind direction might change and expose the "background mast" to $\mathrm{NH}_{3}$ originating from the measurement plot.

\subsubsection{Oasis effect}

An additional effect is the oasis effect, where the emission from a plot in the middle of a "clean" environment will be higher than compared to the same plot located in the middle of a field that is also strongly emitting (for a detailed investigation see Sommer et al., 2003 and Loubet et al., 2010). In the first case, the concentration in the atmosphere above the emitting patch will in general be significantly lower than in the second case, leading to a difference in the concentration gradient driving the emission. In theory, the TAN in the slurry therefore will have more time to penetrate into the soil, and this too could explain higher estimates when the IHF method is used. The oasis effect depends strongly on the plot size and becomes negligible in case the extension of the source area upwind of the mast exceeds $\sim 50 \mathrm{~m}$. For a circle with a radius of $20 \mathrm{~m}$ Loubet et al. (2010) calculated an effect between $5 \%$ for unstable and about $15 \%$ for stable conditions. Table 1 summarises the potential biases of small and medium plot size methods.

\subsubsection{Assessment of bLS and ZINST}

In the past years, the bLS method has been evaluated in detail with reported accuracies better than $10 \%$ under most circumstances (Flesch et al., 2004, 2005; McBain and Desjardins, 2005; Gao et al., 2009, 2010). The bLS is considered to be currently among the most accurate micrometeorological techniques to calculate dispersion and determine emission rates (Denmead, 2008; Laubach, 2010; Loubet et al., 2010). It calculates emissions accurately provided that there are homogenously emitting source areas (or well represented point sources), a precise monitoring of $c_{\mathrm{bgd}}$, and a wind field sufficiently undisturbed by obstacles.

A combination of bLS modeling and IHF method, the ZINST approach, was used by Menzi et al. (1998). In their calculations, they used values of $0.7 \mathrm{~cm}$ for $z_{0}$ (aerodynamic roughness length of the surface) and a factor of 8 for $\bar{u} \bar{c} / F$ ( $F$ denoting the emission flux from a radial source area) (Katz, 1996). They applied a downward correction in the order of $15 \%$ for the horizontal turbulent diffusion as suggested by Denmead and Raupach (1993). A re-assessment based on the new WindTrax software yields systematically lower $\bar{u} \bar{c} / F$ values of around 10 to $15 \%$, thus in the same order of magnitude as the correction suggested by Denmead and Raupach. The WindTrax bLS approach implicitly takes into account the horizontal turbulent diffusion and therefore the two approaches agree.

\subsection{Limitations of vertical flux methods}

\subsubsection{Limited fetch, advection and footprint correction}

Whereas the horizontal flux approaches discussed above rely on a limited source area, the vertical flux methods (AGM or EC) are, in the simple case, based on the assumption of 
Table 1. Summary of methodological issues and their potential bias effects on different $\mathrm{NH}_{3}$ flux measurement methods.

\begin{tabular}{|c|c|c|c|}
\hline Flux method & Methodological issue & Potential effect & $\begin{array}{l}\text { Chance of } \\
\text { occurrence }\end{array}$ \\
\hline \multirow[t]{3}{*}{ chambers } & linear interpolation & underestimate up to $50 \%$ & likely \\
\hline & wall effects on $\mathrm{NH}_{3}$ & underestimate/hysteresis up to $50 \%$ & likely \\
\hline & ventilation & $\begin{array}{l}\text { both under-/overestimate, } \\
\text { depending on fan speed up to } 50 \%\end{array}$ & likely \\
\hline \multirow[t]{6}{*}{ IHF on medium plots } & cup anemometer \& gusts & overestimate & unlikely \\
\hline & cup anemometer $<1 \mathrm{~m} \mathrm{~s}^{-1}$ & underestimate & likely \\
\hline & turbulent backflow & $\begin{array}{l}\text { overestimate } \sim 5-20 \% \text {, } \\
\text { (see Denmead, } 1995 \text {, and ref. therein) }\end{array}$ & high \\
\hline & tower too small & underestimate & low \\
\hline & impinger error & overestimate & unlikely \\
\hline & oasis effect & overestimate 5 to $10 \%$ & high \\
\hline
\end{tabular}

an unlimited homogeneous source area or fetch. In order to account for limited fetch conditions and associated vertical flux divergence, the flux footprint has to be determined. It describes the spatial weight distribution of the upwind surface area contributing to the flux measured at a given point (Schmid, 2002). Footprint analysis (Neftel et al., 2008) can be used to correct for the flux divergence (e.g. Spirig et al., 2010; Sintermann et al., 2011a). This is possible for the typical situation of slurry application with strongly emitting surfaces surrounded by areas with a negligible exchange flux. Alternatively, a model such as FIDES may be used to calculate the "advection error" (Loubet et al., 2009). The models used to correct for the limited fetch assume ideal conditions, such as flat surfaces with homogeneous roughness and a wind profile that can be represented by a power law or a logarithmic function. The footprint is usually defined by few parameters (measurement height $z_{\mathrm{m}}$, standard deviation of lateral wind component $\sigma_{v}$, friction velocity $u_{*}$, mean wind speed $\bar{u}$, and dimensionless stability $z / L)$. Based on Monin-Obukhov surface layer similarity, the use of $z_{0}$ or $\bar{u}$ as input parameter is equivalent under ideal conditions (see Neftel et al., 2008).

The accuracy of the footprint or advection correction depends on the stability and is poor for stagnant (non turbulent) conditions. For unstable daytime conditions the uncertainty of the correction is generally lower than $20 \%$ (Neftel et al., 2008; Tuzson et al., 2010). The larger the footprint correction, the larger will also be the relative error of the final footprint corrected flux. As a rule of thumb, the field of interest, for which the emission has to be determined, should contribute about half or more to the flux footprint.

\subsubsection{High-frequency correction of EC measurements}

As mentioned above (Sect. 2.2.5) high-frequency attenuation effects in EC measurements can be corrected for by the ogive method. The observed damping is often parameterised as a function of horizontal wind speed in order to decrease the scatter of the individual corrections (Ammann et al., 2006). Optical detection systems such as tunable diode laser systems or quantum cascade laser systems as well as CIMS do have a high enough time resolution and sensitivity to be used in EC approaches (Whitehead et al., 2008; Sintermann et al., $2011 \mathrm{~b}$ ), but it is the damping in the inlet system which reduces the high-frequency response of the measurement system as a whole. The ogive method (and similar spectral approaches) implies that below a certain frequency, turbulent variations of $\mathrm{NH}_{3}$ passed the inlet line undamped. This is perhaps an oversimplification (Ellis et al., 2010; Sintermann et al., 2011b) that may lead to an underestimation of the highfrequency correction und thus of the final flux.

\subsection{A proposed plausibility check for initial volatilisation from slurry}

A common observation in most experiments is that the temporal course of the $\mathrm{NH}_{3}$ emission from an area where slurry was instantaneously applied can be described by a MichaelisMenten equation (Eqs. 4 and 5) as it is done in the ALFAM framework (Søgaard et al., 2002) or by a bi-exponential decay (Sintermann et al., 2011a). The Michaelis-Menten function is often used to describe the temporal behaviour of biological systems showing non-linear exhausting behaviour. Using this functional time dependence, the initial volatilisation flux (immediately after slurry spreading) can be empirically determined and may be compared to physical-chemical constraints of $\mathrm{NH}_{3}$ volatilisation.

Given that the temporal behaviour of the $\mathrm{NH}_{3}$ volatilisation after slurry broad-spreading is well represented by the Michaelis-Menten equation (as expected in the ALFAM model), the initial emission flux is directly proportional to the ratio of the total integrated emission $N_{\max }$ (Eq. 6).

Considering, for simplification, slurry as an ideal solution initially containing a given amount of TAN, the theoretical flux immediately after slurry application can be calculated using the slurry TAN content, $\mathrm{pH}$, surface temperature 
and turbulence characteristics. Assuming liquid-gas phase equilibrium, the initial $\mathrm{NH}_{3}$ concentration $c_{\text {ini }}\left(z_{0}^{\prime}\right)$ above the hypothetical slurry surface can be inferred with the help of Henry's law and the $\mathrm{NH}_{3}$ protonation constant (Génermont and Cellier, 1997; Spirig et al., 2010):

$c_{\text {ini }}\left(z_{0}^{\prime}\right)=\frac{\left[\mathrm{NH}_{4}^{+}\right] \cdot 10^{4.1218-4507 / T\left(z_{0}^{\prime}\right)}}{\left[\mathrm{H}^{+}\right] \cdot 10^{-9}}$,

$c_{\text {ini }}\left(z_{0}^{\prime}\right)$ in ppb, $\left[\mathrm{NH}_{4}^{+}\right]$and $\left[\mathrm{H}^{+}\right]$in $\operatorname{moll}^{-1}$, and $T\left(z_{0}^{\prime}\right)$ in $\mathrm{K}$.

The concentration $c_{\text {ini }}\left(z_{0}^{\prime}\right)$ represents the surface $\mathrm{NH}_{3}$ emission potential of applied slurry and can be used to compute the initial flux $F_{\text {ini }}$ one would expect to measure at a certain height over the emitting slurry. $F_{\text {ini }}$ relates to $c_{\text {ini }}\left(z_{0}^{\prime}\right)$ via the corresponding air concentration at a reference height above the zero-plane displacement, i.e. $c_{\text {ini }}(z-d)$, and the aerodynamic and viscous sublayer resistances $R_{\mathrm{a}}$ and $R_{\mathrm{b}}$ (e.g. Flechard et al., 2010):

$F_{\text {ini }}=\frac{c_{\text {ini }}\left(z_{0}^{\prime}\right)-c_{\text {ini }}(z-d)}{R_{\mathrm{a}}(z-d)+R_{\mathrm{b}}}$.

Using the corresponding relationship for temperature, $T_{\text {ini }}\left(z_{0}^{\prime}\right)$ can be extrapolated down to the surface from the air temperature $T_{\text {ini }}(z-d)$ and the sensible heat flux measured by ultrasonic anemometer.

Contrasting this slurry derived estimate of $F_{\text {ini }}$ to the respective flux measurement derived value determined by fitting the proposed time dependent function (MichaelisMenten type: see Sect. 2.4.1 or bi-exponential following Sintermann et al., 2011a) provides a rough test for the physical and chemical plausibility of the measured $\mathrm{NH}_{3}$ emission. Such an investigation can only be made in case an experiment was well documented in the original publication, which was often the exception rather than the rule. Table 2 lists the set of input parameters needed for the calculation of the expected distribution of $F_{\text {ini }}$. Our analysis includes an uncertainty analysis based on a Monte Carlo simulation that reflects the uncertainty of the input parameters. For this analysis, two examples of measurements reported in Menzi et al. (1998) and Sintermann et al. (2011a) were used as an illustration (Fig. 5). Required input parameters are not precisely known and are associated with an uncertainty range. To reflect this situation, a large number of random sets of input parameters was sampled from normal-distributions, characterised either by specified mean values and standard deviations (or according to reported $\mathrm{min} / \mathrm{max}$ values) or were arbitrarily chosen to reflect the range of probable values. Estimation of the upper limit of the initial fluxes has a large uncertainty as the determining factors themselves are not precisely known. Especially the uncertainty range of the $\mathrm{pH}$ results in an asymmetrical distribution of the initial fluxes that is amplified with the corresponding uncertainty range of $T_{\mathrm{ini}}\left(z_{0}^{\prime}\right)$. The measured cumulated emissions given in Menzi et al. (1998) were described by fitting Eq. (4) (Michaelis-Menten) to derive the

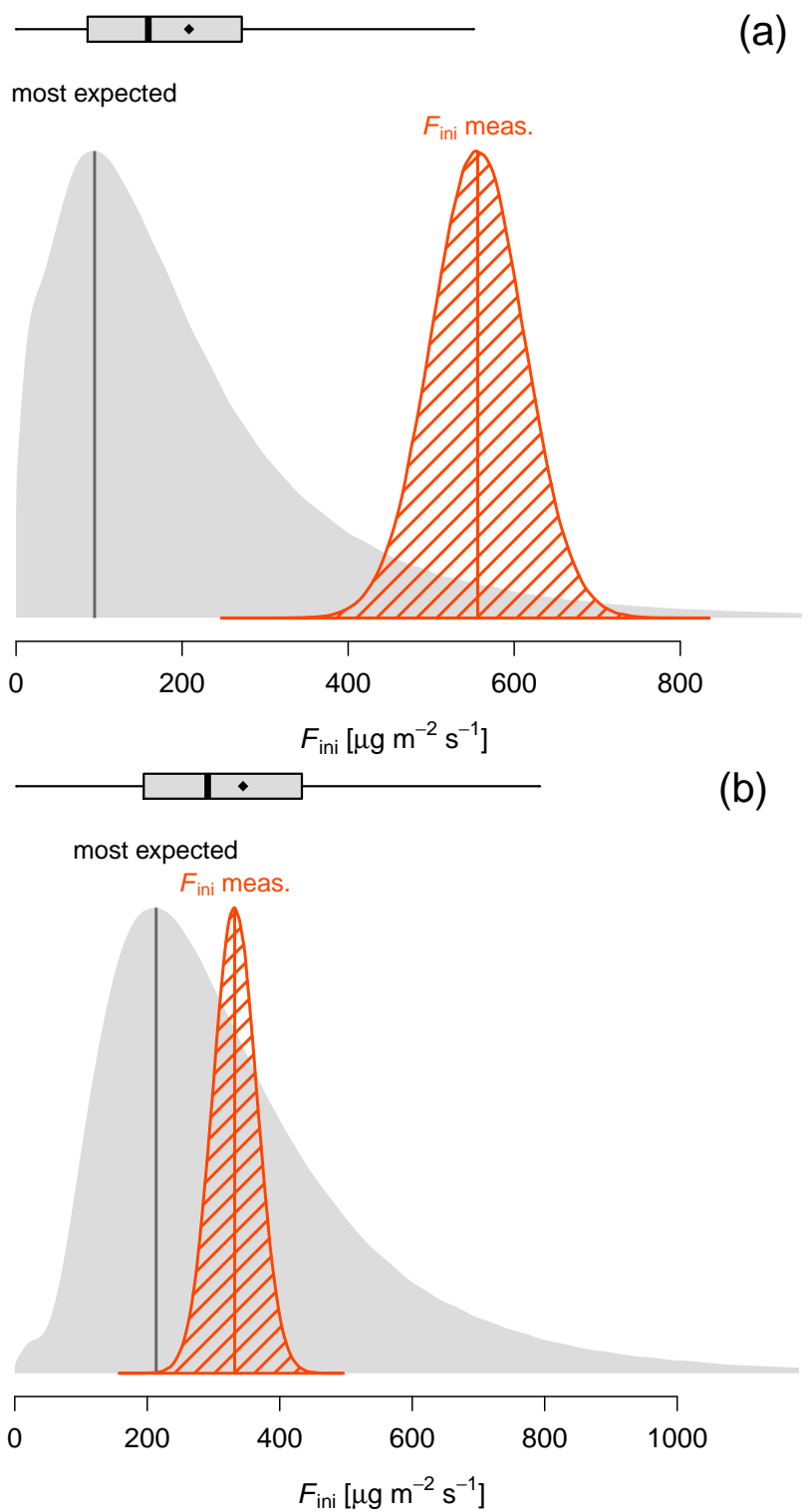

Fig. 5. Distribution of the initial flux $\left(F_{\text {ini }}\right)$ immediately after slurry spreading, derived from slurry and turbulence characteristics (grey) and from flux measurements (red) for two cases as in Table 2: (a) Menzi et al. (1998), and (b) Sintermann et al. (2011a).

initial emission rate (Eq. 6). This $F_{\text {ini }}$ was assigned an uncertainty (standard deviation of the Gaussian distribution) of $10 \%$. The example in Fig. $5 \mathrm{~b}$ shows a minor difference in the $F_{\text {ini }}$ results from the two independent methods, well within the uncertainty range of the slurry volatilisation estimate. In contrast, the other example in Fig. 5a exhibits a clear deviation of the measured value from the slurry volatilisation estimate, which cannot be explained by the uncertainty distributions. Table 2 summarises the results of Fig. 5 together with two corresponding evaluations using average data published by Huijsmans et al. (2001), showing a similar discrepancy as in Fig. 5a. As the total cumulative loss can be considered 
Table 2. Comparison of measured ( $\left.F_{\text {ini,meas }}\right)$ and (from slurry and atmospheric properties) estimated initial flux $\left(F_{\text {ini,est }} ; 25,50\right.$, and $75 \%$ denote median and quartiles of the $F_{\text {ini,est }}$ distribution) from slurry applied to grassland using splash plate; values derived from (a) Menzi et al. (1998)/Katz (1996), (b) Huijsmans et al. (2001), and (c) Sintermann et al. (2011a).

\begin{tabular}{|c|c|c|c|c|c|}
\hline & & (a) & (b) & (b) & (c) \\
\hline slurry type & & cattle & cattle & pig & cattle \\
\hline crop & & grass & grass & grass & grass \\
\hline canopy height & [m] & $0.07 \pm 0.02^{\mathrm{a}}$ & $0.072 \pm 0.03^{b}$ & $0.072 \pm 0.03^{b}$ & $0.05 \pm 0.02^{\mathrm{a}}$ \\
\hline $\mathrm{pH}$ & & $7.4 \pm 0.2$ & $7.0 \pm 0.4^{\mathrm{a}}$ & $7.5 \pm 0.4^{\mathrm{a}}$ & $7.49 \pm 0.19^{b}$ \\
\hline TAN & {$\left[\mathrm{g}^{-1}\right]$} & $1.3 \pm 0.1^{\mathrm{a}}$ & $2.2 \pm 1.2^{\mathrm{b}}$ & $5.4 \pm 1.6^{b}$ & $1.18 \pm 0.05^{b}$ \\
\hline$T$ & {$[\mathrm{~K}]$} & $292.0 \pm 3^{\mathrm{a}}$ & $287.6 \pm 10^{\mathrm{a}}$ & $287.6 \pm 10^{\mathrm{a}}$ & $295.0 \pm 3^{\mathrm{a}}$ \\
\hline$H$ & {$\left[\mathrm{~W} \mathrm{~m}^{-2}\right]$} & $50 \pm 40$ & $100 \pm 50$ & $100 \pm 50$ & $88 \pm 20^{\mathrm{a}}$ \\
\hline$L$ & {$[\mathrm{~m}]$} & $-10 \pm 8$ & $-10 \pm 8$ & $-10 \pm 8$ & $-4.6 \pm 2^{\mathrm{a}}$ \\
\hline$U$ & {$\left[\mathrm{~m} \mathrm{~s}^{-1}\right]$} & $2.0 \pm 1.5^{\mathrm{a}}$ & $3.2 \pm 2.5^{\mathrm{a}}$ & $3.2 \pm 2.5^{\mathrm{a}}$ & $1.2 \pm 0.5^{\mathrm{a}}$ \\
\hline$u_{*}$ & {$\left[\mathrm{~m} \mathrm{~s}^{-1}\right]$} & - & - & - & $0.18 \pm 0.05^{\mathrm{a}}$ \\
\hline$z_{0}$ & {$[\mathrm{~m}]$} & $0.025 \pm 0.015$ & $0.05 \pm 0.03$ & $0.05 \pm 0.03$ & $0.027 \pm 0.01^{\mathrm{a}}$ \\
\hline$c_{\text {bgd }}$ & {$\left[\mu \mathrm{g} \mathrm{m}^{-3}\right]$} & $5 \pm 4$ & $8 \pm 5$ & $8 \pm 5$ & $5.8 \pm 2^{\mathrm{a}}$ \\
\hline $\mathrm{EF}$ & [\% of TAN] & $58.0^{\mathrm{a}}$ & $68.8^{\mathrm{a}}$ & $62.4^{\mathrm{a}}$ & $18.7^{\mathrm{a}}$ \\
\hline$F_{\text {ini,meas }}$ & {$\left[\mu \mathrm{g} \mathrm{m}^{-2} \mathrm{~s}^{-1}\right]$} & 556 & $862^{\mathrm{a}}$ & $1894^{\mathrm{a}}$ & $332^{\mathrm{a}}$ \\
\hline$F_{\text {ini,est }} 25 \%$ & {$\left[\mu \mathrm{g} \mathrm{m}^{-2} \mathrm{~s}^{-1}\right]$} & 86 & 26 & 231 & 195 \\
\hline$F_{\text {ini,est }} 50 \%$ & {$\left[\mu \mathrm{g} \mathrm{m}^{-2} \mathrm{~s}^{-1}\right]$} & 159 & 86 & 707 & 291 \\
\hline$F_{\text {ini,est }} 75 \%$ & {$\left[\mu \mathrm{g} \mathrm{m}^{-2} \mathrm{~s}^{-1}\right]$} & 272 & 244 & 1938 & 433 \\
\hline
\end{tabular}

${ }^{\mathrm{a}}$ When value given, ${ }^{\mathrm{b}}$ when mean value and standard deviation given.

proportional to the initial emission flux (Eq. 6) the plausibility check for the initial flux represents a constraint also for the total emission loss. The large bias between slurry volatilisation derived $F_{\text {ini }}$ and the initial flux values determined from the emissions measurements in Menzi et al. (1998) and Huijsmans et al. (2001) suggests an overestimation present in the corresponding EFs.

\subsection{Consequences for emission inventories}

EFs for slurry application are generally defined for the reference case using splash plate spreading for annual average conditions. For example, in the Swiss inventory the EF of $50 \%$ for cattle slurry refers to a mean TAN content of $1.15 \mathrm{~g} \mathrm{l}^{-1}$, an application rate of $30 \mathrm{~m}^{3}$ per hectare, a mean air humidity saturation deficit of 4.2 mbar. Application mainly on warm days (air temperature $>2.2{ }^{\circ} \mathrm{C}$ + mean temperature of May to November) shows $10 \%$ increased emissions, and application after 18:00 a reduction of $20 \%$ in reference to the base case (see http: //www.agrammon.ch/assets/Downloads/Dokumentation

Technische_Parameter_20100309_korr_20100705.pdf).

These modifications of the reference case EF are based on the empirical model published by Menzi et al. (1998). As mentioned earlier, this model does not take the DM into account, although several authors have recommended the inclusion of DM as a driving parameter (see e.g. Sommer and Olesen, 1991; Misselbrook et al., 2004). On a European average we estimate that around $30 \%$ to $40 \%$ of the total $\mathrm{NH}_{3}$ emissions are associated to field losses after application of slurry. These estimates are based on the assumption of broadspreading-only application, which is a first approach simplification and probably yields upper range estimates. By comparison, the ECETOC report (ECETOC, 1994) indicates that field application of slurry accounts for $31 \%$ of the total $\mathrm{NH}_{3}$ emissions (Table 12, page 44). Misselbrook et al. (2006) indicate $34 \%$ for the year 2004 for the UK, Valli et al. (2001) $30 \%$ for Italy, Döhler et al. (2002) $35 \%$ for Germany. Assuming that the increasing use of low emission techniques such as trailing hose, trailing shoes, and injection will yield a $50 \%$ reduction in relation to the splash plate reference case, the share of field losses to the calculated total $\mathrm{NH}_{3}$ emissions reduces from $35 \%$ to around $20 \%$. Potentially lowering the reference case EF roughly by a factor of 0.5 (Figs. 2a and 3) would shift this contribution from $20 \%$ to around $12 \%$.

Over the last few years a great effort has been undertaken to relate $\mathrm{NH}_{3}$ emission inventories and ambient $\mathrm{NH}_{3}$ concentration measurements. At the present stage it is assumed that the calculated emission levels, together with modelled atmospheric transport, chemistry, and deposition, successfully predict the measured ambient concentrations (Thöni et al., 2004; van Pul et al., 2008; Bleeker et al., 2009). Consequently, a systematic reduction of field losses in emission inventories would have to be counterbalanced by greater losses in the animal housings, during storage or during grazing, or by reduced atmospheric deposition. However, similar to the analysis of the uncertainty of the initial fluxes it remains to be investigated how precise the relation between emissions and ambient concentration is. Such analysis is further 
complicated by the fact that over the last $20 \mathrm{yr}$ low emission techniques have been promoted. It seems possible that compensating errors have preserved the established sourcereceptor relationships: high reference EFs could be compensated by over-estimated reduction factors resulting from the abatement measures. The reduction effect of band spreading relative to splash plate spreading depends on the vegetation canopy height. For application onto bare soil or short grass $\mathrm{NH}_{3}$ emission reductions by about $10 \%$ have been reported (Döhler et al., 2002), whereas application to canopies of $30 \mathrm{~cm}$ height yields reductions between 30 and $50 \%$ (Thorman et al., 2008). It is likely that even though low emission techniques are being increasingly used, a significant fraction might be applied to bare soils and short grass canopies.

\section{Conclusions}

In the present article we have compiled over 350 measurements of $\mathrm{NH}_{3}$ emission factors from field application of slurry published between 1991 and 2011 and review common measurement approaches to determine $\mathrm{NH}_{3}$ emissions. In the following the results and considerations of Sect. 3 are concisely summarised and some final conclusions and recommendations are given.

- For slurry distributed by the splash-plate technique, a considerable discrepancy of at least a factor of 2 between EFs from earlier medium-plot/IHF measurements and recent field scale measurements has been found (Fig. 2a).

- This discrepancy persist, even if environmental (and slurry) parameters are taken into account with the help of existing empirical model parameterisations (Fig. 3).

- A careful review of the potentials for methodological errors in the various emission measurement techniques gave no sufficient sources of (systematic) uncertainty to explain the observed discrepancy. In contrast, from current knowledge (Sects. 3.1-3.4.2) we do not expect a pronounced difference between the emissions from medium scale plots with radius $>20 \mathrm{~m}$ (IHF) and those determined on the field scale typical for agricultural practice.

We thus report on the paradoxical situation that the presumably most robust measuring techniques applied on medium plot scales yielded much higher emissions compared to recent field scale measurements using more complex and sensitive approaches. The discussed medium and field scale approaches are supposed to be equally suitable for the determination of $\mathrm{NH}_{3}$ emissions as long as realistic agricultural practice is reflected in the experiments. We regard small scale approaches using a dynamic chamber technique as useful in case the goal is to characterise relative efficiencies of different management options and/or relative temperature and slurry composition influences. However, we strongly recommend that the determination of slurry application losses should be based on measurements which, unlike dynamic chamber techniques, do not change the characteristics of the $\mathrm{NH}_{3}$ exchange at the surface.

- While there is no definite evidence which group of measurements (see Fig. 2a) represents reality more appropriately, a plausibility analysis for initial emission fluxes suggests that some of the earlier medium plot/IHF results show a bias towards overestimation (Table 2 and Fig. 5).

- Since a mechanistic explanation for the observed deviation could not yet be identified, a correction of the earlier measurements and corresponding parameterisations is presently not possible.

Consequently, new series of measurements are urgently needed in order to systematically compare emissions from medium scale plots and field scale measurements under identical conditions using a range of different measurement techniques, and to continue characterising $\mathrm{NH}_{3} \mathrm{EFs}$ in terms of the influence of slurry composition and application method, soil properties and meteorology. Such experiments essentially should report on the parameters required to perform a plausibility check, e.g. comparing initial fluxes, and to apply and develop process oriented models (e.g. van der Molen et al., 1990; Hutchings al., 1996; Génermont and Cellier, 1997; Sommer and Olesen, 2000; Beuning et al., 2008).

The present assessment signifies that current emission inventories likely need to be updated including the findings of the new generation of field scale $\mathrm{NH}_{3}$ emission measurements. At length, the proposed new measurement series should add more comprehensive datasets to be included in the inventory methodologies. It is clear that well validated national or European empirical relationships are preferable over generalised EFs, but ultimately emission inventories ought to be based on process oriented models. However, it has to be kept in mind that every model needs to be calibrated and validated by field measurements and thus will reproduce all systematic biases contained in the measurements. 
Table A1. Used $\mathrm{NH}_{3}$ EFs and related data.

\begin{tabular}{|c|c|c|c|c|c|c|c|c|c|c|c|c|c|}
\hline Reference & Spread. & Crop & Method & $\begin{array}{l}\text { Trial Scale } \\
{\left[\text { class or } \mathrm{m}^{2} \text { ] }\right.}\end{array}$ & Trial Yr & Sl. Type & $\begin{array}{l}U \\
{\left[\mathrm{~ms}^{-1}\right]}\end{array}$ & $\begin{array}{l}\text { TAN } \\
{\left[\mathrm{g} \mathrm{kg}^{-1}\right]}\end{array}$ & $\begin{array}{l}\mathrm{TN} \\
{\left[\mathrm{g} \mathrm{kg}^{-1}\right]}\end{array}$ & $\mathrm{pH}$ & $\begin{array}{l}\mathrm{DM} \\
{[\%]}\end{array}$ & $\begin{array}{l}\text { App. Rate } \\
{\left[\mathrm{m}^{3} \mathrm{ha}^{-1}\right]}\end{array}$ & $\begin{array}{l}\mathrm{EF} \\
{[\%]}\end{array}$ \\
\hline \multirow[t]{5}{*}{ Amon et al. (2006) } & $\mathrm{TH}$ & grass & DC & small plot & 2000 & cattle & & 1.82 & 3.25 & 7.80 & 5.7 & 40.0 & 8.4 \\
\hline & $\mathrm{TH}$ & grass & DC & small plot & 2000 & cattle & & 1.73 & 3.66 & 7.88 & 4.2 & 40.0 & 3.6 \\
\hline & $\mathrm{TH}$ & grass & $\mathrm{DC}$ & small plot & 2000 & cattle & & 1.55 & 2.48 & 7.78 & 4.2 & 40.0 & 11.7 \\
\hline & $\mathrm{TH}$ & grass & $\mathrm{DC}$ & small plot & 2000 & cattle & & 1.64 & 3.84 & 7.55 & 7.8 & 40.0 & 13.5 \\
\hline & $\mathrm{TH}$ & grass & $\mathrm{DC}$ & small plot & 2000 & cattle & & 1.30 & 3.85 & 7.58 & 7.5 & 40.0 & 13.6 \\
\hline \multirow[t]{6}{*}{ ART, unpublished } & SP & grass & WT & field scale & 2008 & cattle & 2.0 & 0.86 & 1.04 & 7.30 & 1.0 & 33.5 & 6.7 \\
\hline & SP & grass & WT & field scale & 2009 & cattle & 1.1 & 1.02 & 1.42 & 7.60 & 2.0 & 27.5 & 15.6 \\
\hline & SP & grass & WT & field scale & 2010 & cattle & 1.1 & 1.13 & 1.65 & 7.20 & 0.6 & 30.7 & 12.1 \\
\hline & $\mathrm{TH}$ & grass & WT & 1296 & 2010 & cattle & 1.0 & 1.11 & 2.28 & 7.30 & 3.8 & 26.4 & 16.2 \\
\hline & SP & grass & WT & 1296 & 2010 & cattle & 1.0 & 1.18 & 2.28 & 7.30 & 3.8 & 26.9 & 23.2 \\
\hline & SP & grass & WT & field scale & 2010 & cattle & 3.0 & 1.22 & 1.84 & 7.50 & 0.8 & 29.6 & 26.3 \\
\hline \multirow[t]{12}{*}{ Balsari et al. (2008) } & SP & grass & WTu & small plot & & cattle & 0.6 & 2.10 & & 7.60 & 5.7 & 20.0 & 58.7 \\
\hline & SP & grass & WTu & small plot & & cattle & 0.6 & 2.10 & & 7.80 & 4.4 & 21.2 & 50.5 \\
\hline & SP & grass & WTu & small plot & & cattle & 0.0 & 2.10 & & 7.60 & 5.7 & 20.0 & 20.0 \\
\hline & SP & grass & WTu & small plot & & cattle & 0.0 & 2.10 & & 7.80 & 4.4 & 21.2 & 20.8 \\
\hline & SP & grass & WTu & small plot & & cattle & 0.0 & 2.10 & & 7.60 & 5.7 & 11.4 & 26.8 \\
\hline & SP & grass & WTu & small plot & & cattle & 0.0 & 2.10 & & 7.80 & 4.4 & 12.1 & 23.1 \\
\hline & SP & grass & WTu & small plot & & cattle & 0.6 & 1.50 & & 7.50 & 7.1 & 20.6 & 52.7 \\
\hline & SP & grass & WTu & small plot & & cattle & 0.6 & 1.70 & & 7.80 & 4.4 & 21.2 & 32.4 \\
\hline & SP & grass & WTu & small plot & & cattle & 0.0 & 1.50 & & 7.50 & 7.1 & 20.6 & 26.1 \\
\hline & SP & grass & WTu & small plot & & cattle & 0.0 & 1.70 & & 7.80 & 4.4 & 21.2 & 20.9 \\
\hline & SP & grass & WTu & small plot & & cattle & 0.0 & 1.50 & & 7.50 & 7.1 & 11.8 & 27.5 \\
\hline & SP & grass & WTu & small plot & & cattle & 0.0 & 1.70 & & 7.80 & 4.4 & 12.1 & 18.7 \\
\hline \multirow[t]{12}{*}{ Bhandral et al. (2009) } & SP & arable & WTu & small plot & 2005 & cattle & 1.0 & 1.20 & 1.80 & 7.00 & 2.8 & 120.0 & 39.2 \\
\hline & SP & arable & WTu & small plot & 2005 & cattle & 1.0 & 1.30 & 2.40 & 6.80 & 6.8 & 100.0 & 37.5 \\
\hline & SP & arable & WTu & small plot & 2005 & cattle & 1.0 & 1.10 & 1.50 & 7.40 & 2.2 & 126.0 & 51.0 \\
\hline & SP & arable & WTu & small plot & 2005 & cattle & 1.0 & 1.20 & 2.40 & 6.80 & 7.2 & 104.0 & 36.7 \\
\hline & SP & arable & WTu & small plot & 2005 & cattle & 1.0 & 1.00 & 1.20 & 8.10 & 1.3 & 133.0 & 16.3 \\
\hline & SP & arable & WTu & small plot & 2005 & cattle & 1.0 & 1.10 & 2.50 & 7.50 & 7.0 & 109.0 & 39.1 \\
\hline & SP & arable & WTu & small plot & 2006 & cattle & 1.0 & 0.90 & 1.70 & & 2.8 & 124.0 & 38.0 \\
\hline & SP & arable & WTu & small plot & 2006 & cattle & 1.0 & 1.00 & 2.10 & & 6.0 & 115.0 & 39.3 \\
\hline & SP & arable & WTu & small plot & 2006 & cattle & 1.0 & 0.90 & 1.30 & & 0.2 & 141.0 & 39.1 \\
\hline & SP & arable & WTu & small plot & 2006 & cattle & 1.0 & 1.00 & 2.00 & & 5.7 & 120.0 & 37.4 \\
\hline & SP & arable & WTu & small plot & 2006 & cattle & 1.0 & 0.60 & 1.00 & & 1.3 & 127.0 & 13.4 \\
\hline & SP & arable & WTu & small plot & 2006 & cattle & 1.0 & 1.00 & 2.00 & & 4.6 & 70.0 & 41.9 \\
\hline \multirow[t]{4}{*}{ Bittman et al. (2005) } & SP & grass & $\mathrm{IHF}$ & 400 & 2000 & cattle & 2.1 & 1.40 & 2.30 & 7.30 & 6.1 & 56.0 & 57.5 \\
\hline & SP & grass & IHF & 400 & 2000 & cattle & 1.6 & 1.20 & 2.00 & 7.20 & 5.5 & 54.0 & 37.2 \\
\hline & SP & grass & IHF & 400 & 2001 & cattle & 1.9 & 0.90 & 2.10 & 7.90 & 5.6 & 66.0 & 63.6 \\
\hline & SP & grass & IHF & 400 & 2001 & cattle & 4.7 & 0.70 & 1.70 & 7.20 & 5.1 & 69.0 & 66.5 \\
\hline \multirow[t]{2}{*}{ Chantigny et al. (2004) } & SP & arable & WTu & small plot & 2000 & pig & & 6.70 & 9.70 & 7.70 & 5.9 & 90.0 & 27.1 \\
\hline & SP & arable & WTu & small plot & 2000 & pig & & 5.40 & 7.80 & 8.10 & 3.3 & 90.0 & 28.5 \\
\hline \multirow[t]{15}{*}{ Chantigny et al. (2009) } & SP & arable & WTu & small plot & 2004 & pig & & 3.50 & 7.20 & 7.40 & 5.2 & 14.0 & 47.6 \\
\hline & SP & arable & WTu & small plot & 2004 & pig & & 3.70 & 6.00 & 7.70 & 2.8 & 16.0 & 33.1 \\
\hline & SP & arable & WTu & small plot & 2004 & pig & & 3.20 & 4.70 & 8.10 & 1.6 & 34.0 & 42.6 \\
\hline & SP & arable & WTu & small plot & 2004 & pig & & 3.70 & 5.40 & 8.00 & 2.6 & 16.0 & 31.7 \\
\hline & SP & arable & WTu & small plot & 2004 & pig & & 2.80 & 4.60 & 8.30 & 1.0 & 25.0 & 37.7 \\
\hline & SP & arable & WTu & small plot & 2005 & pig & & 5.30 & 6.40 & 7.50 & 7.6 & 21.0 & 30.3 \\
\hline & SP & arable & WTu & small plot & 2005 & pig & & 5.10 & 6.30 & 7.80 & 4.1 & 24.0 & 34.3 \\
\hline & SP & arable & WTu & small plot & 2005 & pig & & 3.50 & 4.10 & 8.10 & 3.2 & 34.0 & 33.8 \\
\hline & SP & arable & WTu & small plot & 2005 & pig & & 4.90 & 6.10 & 8.30 & 4.8 & 23.0 & 24.2 \\
\hline & SP & arable & WTu & small plot & 2005 & pig & & 4.40 & 5.10 & 8.30 & 2.7 & 28.0 & 22.2 \\
\hline & SP & arable & WTu & small plot & 2005 & pig & & 5.40 & 6.80 & 8.70 & 5.0 & 21.0 & 24.1 \\
\hline & SP & arable & WTu & small plot & 2005 & pig & & 3.40 & 4.10 & 8.20 & 1.2 & 24.0 & 10.3 \\
\hline & SP & arable & WTu & small plot & 2005 & pig & & 3.50 & 4.30 & 8.40 & 1.3 & 34.0 & 15.2 \\
\hline & SP & arable & WTu & small plot & 2005 & pig & & 5.60 & 6.30 & 8.80 & 2.6 & 24.0 & 14.2 \\
\hline & SP & arable & WTu & small plot & 2005 & pig & & 4.70 & 5.10 & 9.00 & 1.2 & 30.0 & 19.0 \\
\hline
\end{tabular}


Table A1. Continued.

\begin{tabular}{|c|c|c|c|c|c|c|c|c|c|c|c|c|c|}
\hline Reference & Spread. & Crop & Method & $\begin{array}{l}\text { Trial Scale } \\
{\left[\text { class or } \mathrm{m}^{2} \text { ] }\right.}\end{array}$ & Trial Yr & Sl. Type & $\begin{array}{l}U \\
{\left[\mathrm{~ms}^{-1}\right]}\end{array}$ & $\begin{array}{l}\text { TAN } \\
{\left[\mathrm{g} \mathrm{kg}^{-1}\right]}\end{array}$ & $\begin{array}{l}\mathrm{TN} \\
{\left[\mathrm{g} \mathrm{kg}^{-1}\right]}\end{array}$ & $\mathrm{pH}$ & $\begin{array}{l}\mathrm{DM} \\
{[\%]}\end{array}$ & $\begin{array}{l}\text { App. Rate } \\
{\left[\mathrm{m}^{3} \mathrm{ha}^{-1}\right]}\end{array}$ & $\begin{array}{l}\mathrm{EF} \\
{[\%]}\end{array}$ \\
\hline \multirow[t]{12}{*}{ Gärtner et al. (2008) } & SP & arable & MBM & field scale & 2005 & pig & & 4.33 & & & 4.0 & 15.0 & 8.9 \\
\hline & $\mathrm{TH}$ & arable & MBM & field scale & 2005 & pig & & 4.33 & & & 4.0 & 14.0 & 4.1 \\
\hline & PV & arable & MBM & field scale & 2005 & pig & & 4.33 & & & 4.0 & 12.0 & 7.7 \\
\hline & $\mathrm{TH}$ & arable & MBM & field scale & 2006 & pig & & 4.33 & & & 4.0 & 38.0 & 9.6 \\
\hline & $\mathrm{TH}$ & arable & MBM & field scale & 2006 & pig & & 4.33 & & & 4.0 & 29.0 & 9.4 \\
\hline & $\mathrm{TH}$ & arable & MBM & field scale & 2006 & pig & & 4.33 & & & 4.0 & 39.0 & 4.2 \\
\hline & $\mathrm{TH}$ & arable & MBM & field scale & 2006 & pig & & 4.33 & & & 4.0 & 17.0 & 5.0 \\
\hline & SP & arable & MBM & field scale & 2006 & pig & & 4.33 & & & 4.0 & 18.0 & 4.5 \\
\hline & $\mathrm{TH}$ & arable & MBM & field scale & 2007 & pig & & 4.33 & & & 4.0 & 27.0 & 8.0 \\
\hline & $\mathrm{TH}$ & arable & MBM & field scale & 2007 & pig & & 4.33 & & & 4.0 & 35.0 & 9.9 \\
\hline & $\mathrm{TH}$ & grass & MBM & field scale & 2007 & pig & & 4.33 & & & 4.0 & 20.0 & 8.4 \\
\hline & TH & arable & MBM & field scale & 2007 & pig & & 4.33 & & & 4.0 & 30.0 & 11.2 \\
\hline \multirow[t]{2}{*}{ Hansen et al. (2003) } & $\mathrm{TH}$ & grass & IHF & 1296 & 1999 & cattle & 3.2 & 1.33 & 2.13 & 7.70 & 3.6 & & 17.0 \\
\hline & $\mathrm{TH}$ & grass & IHF & 1296 & 2000 & cattle & 7.7 & 1.58 & 3.24 & 7.00 & 8.5 & & 45.0 \\
\hline \multirow[t]{49}{*}{ Huijsmans et al. (2001) } & SP & grass & IHF & 1963 & 1989 & cattle & & 3.20 & & 7.00 & & 17.2 & 29.3 \\
\hline & $\mathrm{SP}$ & grass & IHF & 1963 & 1989 & pig & & 6.00 & & 7.50 & & 10.0 & 27.3 \\
\hline & $\mathrm{SP}$ & grass & IHF & 1963 & 1989 & pig & & 5.40 & & & & 12.7 & 68.1 \\
\hline & SP & grass & IHF & 1963 & 1989 & cattle & & 1.60 & & & & 15.4 & 66.1 \\
\hline & SP & grass & IHF & 1963 & 1990 & cattle & & 3.30 & & & & 16.3 & 43.2 \\
\hline & SP & grass & IHF & 1963 & 1990 & cattle & & 3.30 & & & & 12.5 & 47.9 \\
\hline & TS & grass & IHF & 1963 & 1990 & cattle & & 2.20 & & & & 19.0 & 14.7 \\
\hline & TS & grass & IHF & 1963 & 1990 & cattle & & 2.20 & & & & 6.6 & 12.0 \\
\hline & SP & grass & IHF & 1963 & 1990 & cattle & & 2.20 & & & & 19.7 & 47.7 \\
\hline & SP & grass & IHF & 1963 & 1990 & cattle & & 2.20 & & & & 10.2 & 58.3 \\
\hline & SP & grass & IHF & 1963 & 1990 & cattle & & 2.80 & & & & 8.7 & 71.9 \\
\hline & TS & grass & IHF & 1963 & 1990 & cattle & & 2.20 & & & & 17.3 & 31.4 \\
\hline & TS & grass & IHF & 1963 & 1990 & cattle & & 2.20 & & & & 8.4 & 14.6 \\
\hline & SP & grass & IHF & 1963 & 1990 & cattle & & 2.20 & & & & 16.1 & 64.3 \\
\hline & SP & grass & IHF & 1963 & 1990 & cattle & & 2.30 & & & & 9.8 & 44.2 \\
\hline & TS & grass & IHF & 1963 & 1990 & pig & & 6.30 & & & & 14.9 & 31.0 \\
\hline & TS & grass & IHF & 1963 & 1990 & pig & & 6.30 & & & & 7.9 & 16.1 \\
\hline & SP & grass & IHF & 1963 & 1990 & pig & & 6.30 & & & & 17.5 & 67.4 \\
\hline & SP & grass & IHF & 1963 & 1990 & cattle & & 2.30 & & & & 9.9 & 33.9 \\
\hline & TS & grass & IHF & 1963 & 1990 & cattle & & 2.30 & & & & 8.6 & 19.9 \\
\hline & TS & grass & IHF & 1963 & 1990 & pig & & 6.40 & & & & 8.8 & 32.0 \\
\hline & SP & grass & IHF & 1963 & 1990 & cattle & & 2.30 & & & & 8.3 & 61.2 \\
\hline & SP & grass & IHF & 1963 & 1990 & pig & & 6.40 & & & & 8.6 & 49.5 \\
\hline & $\mathrm{SP}$ & grass & IHF & 1963 & 1990 & cattle & & 2.40 & & & & 8.8 & 84.5 \\
\hline & SP & grass & IHF & 1963 & 1990 & cattle & & 2.30 & & & & 9.8 & 51.0 \\
\hline & SP & grass & IHF & 1963 & 1990 & cattle & & 2.20 & & & & 8.7 & 58.4 \\
\hline & SP & grass & IHF & 1963 & 1990 & cattle & & 2.30 & & & & 8.7 & 43.7 \\
\hline & SP & grass & IHF & 1963 & 1990 & cattle & & 2.20 & & & & 8.6 & 83.5 \\
\hline & SP & grass & IHF & 1963 & 1990 & pig & & 3.50 & & & & 8.4 & 66.2 \\
\hline & SP & grass & IHF & 1963 & 1990 & cattle & & 2.00 & & & & 12.7 & 52.0 \\
\hline & SP & grass & IHF & 1963 & 1990 & cattle & & 2.30 & & & & 9.6 & 49.7 \\
\hline & TS & grass & IHF & 1963 & 1991 & cattle & & 1.90 & & & & 10.7 & 21.7 \\
\hline & TS & grass & IHF & 1963 & 1991 & cattle & & 1.90 & & & & 10.6 & 10.6 \\
\hline & SP & grass & IHF & 1963 & 1991 & cattle & & 1.90 & & & & 16.2 & 80.1 \\
\hline & SP & grass & IHF & 1963 & 1991 & cattle & & 1.90 & & & & 15.3 & 64.7 \\
\hline & TS & grass & IHF & 1963 & 1991 & pig & & 5.00 & & & & 12.0 & 14.9 \\
\hline & $\mathrm{TS}$ & grass & IHF & 1963 & 1991 & pig & & 5.00 & & & & 10.6 & 8.5 \\
\hline & SP & grass & IHF & 1963 & 1991 & pig & & 5.00 & & & & 16.3 & 73.7 \\
\hline & SP & grass & IHF & 1963 & 1991 & pig & & 5.00 & & & & 15.2 & 84.9 \\
\hline & TS & grass & IHF & 1963 & 1991 & cattle & & 1.80 & & & & 24.6 & 37.7 \\
\hline & SP & grass & IHF & 1963 & 1991 & cattle & & 1.80 & & & & 13.0 & 97.7 \\
\hline & SP & grass & IHF & 1963 & 1991 & cattle & & 1.50 & & & & 9.8 & 96.7 \\
\hline & $\mathrm{SP}$ & grass & IHF & 1963 & 1991 & cattle & & 1.60 & & & & 14.0 & 70.8 \\
\hline & SP & grass & IHF & 1963 & 1991 & cattle & & 2.50 & & & & 16.4 & 67.8 \\
\hline & SP & grass & IHF & 1963 & 1992 & cattle & & 2.10 & & & & 17.3 & 86.2 \\
\hline & SP & grass & IHF & 1963 & 1992 & cattle & & 2.20 & & & & 17.6 & 84.8 \\
\hline & SP & grass & IHF & 1963 & 1992 & cattle & & 1.80 & & & & 18.7 & 57.2 \\
\hline & $\mathrm{TS}$ & grass & IHF & 1963 & 1992 & cattle & & 2.60 & & & & 13.5 & 30.1 \\
\hline & $\mathrm{TS}$ & grass & IHF & 1963 & 1992 & cattle & & 2.60 & & & & 14.0 & 11.9 \\
\hline
\end{tabular}


Table A1. Continued.

\begin{tabular}{|c|c|c|c|c|c|c|c|c|c|c|c|c|}
\hline Reference & Spread. & Crop & Method & $\begin{array}{l}\text { Trial Scale } \\
{\left[\text { class or } \mathrm{m}^{2} \text { ] }\right.}\end{array}$ & Trial Yr & Sl. Type & $\begin{array}{l}U \\
{\left[\mathrm{~m} \mathrm{~s}^{-1}\right]}\end{array}$ & $\begin{array}{l}\text { TAN } \\
{\left[\mathrm{g} \mathrm{kg}^{-1}\right]}\end{array}$ & $\begin{array}{ll}\mathrm{TN} & \mathrm{pH} \\
{\left[\mathrm{g} \mathrm{kg}^{-1}\right]} & \end{array}$ & $\begin{array}{l}\mathrm{DM} \\
{[\%]}\end{array}$ & $\begin{array}{l}\text { App. Rate } \\
{\left[\mathrm{m}^{3} \mathrm{ha}^{-1}\right]}\end{array}$ & $\begin{array}{l}\mathrm{EF} \\
{[\%]}\end{array}$ \\
\hline & SP & grass & IHF & 1963 & 1992 & cattle & & 2.60 & & & 24.9 & 66.0 \\
\hline & SP & grass & IHF & 1963 & 1992 & cattle & & 2.00 & & & 11.6 & 87.7 \\
\hline & TS & grass & IHF & 1963 & 1992 & cattle & & 2.10 & & & 28.1 & 50.3 \\
\hline & TS & grass & IHF & 1963 & 1992 & cattle & & 2.10 & & & 27.1 & 38.2 \\
\hline & TS & grass & IHF & 1963 & 1992 & cattle & & 2.10 & & & 15.0 & 42.9 \\
\hline & TS & grass & IHF & 1963 & 1992 & cattle & & 2.10 & & & 13.6 & 39.5 \\
\hline & SP & grass & IHF & 1963 & 1992 & cattle & & 2.10 & & & 13.7 & 78.1 \\
\hline & SP & grass & IHF & 1963 & 1992 & cattle & & 2.30 & & & 13.6 & 97.5 \\
\hline & TS & grass & IHF & 1963 & 1992 & cattle & & 2.30 & & & 16.2 & 30.9 \\
\hline & TS & grass & IHF & 1963 & 1992 & cattle & & 2.30 & & & 11.5 & 28.6 \\
\hline & SP & grass & IHF & 1963 & 1992 & cattle & & 2.30 & & & 14.6 & 91.2 \\
\hline & SP & grass & IHF & 1963 & 1992 & cattle & & 2.00 & & & 15.5 & 92.0 \\
\hline & SP & grass & IHF & 1963 & 1992 & cattle & & 2.00 & & & 16.3 & 87.3 \\
\hline & SP & grass & IHF & 1963 & 1993 & cattle & & 2.10 & & & 19.4 & 81.2 \\
\hline & SP & grass & IHF & 1963 & 1993 & cattle & & 2.10 & & & 19.0 & 95.2 \\
\hline & TS & grass & IHF & 1963 & 1993 & cattle & & 2.00 & & & 14.4 & 17.0 \\
\hline & TS & grass & IHF & 1963 & 1993 & cattle & & 2.00 & & & 15.7 & 16.1 \\
\hline & TS & grass & IHF & 1963 & 1993 & cattle & & 2.00 & & & 14.8 & 11.1 \\
\hline & TS & grass & IHF & 1963 & 1993 & cattle & & 2.00 & & & 15.5 & 13.0 \\
\hline & SP & grass & IHF & 1963 & 1993 & cattle & & 2.20 & & & 17.9 & 71.1 \\
\hline & SP & grass & IHF & 1963 & 1993 & cattle & & 2.20 & & & 18.5 & 71.9 \\
\hline & TS & grass & IHF & 1963 & 1993 & cattle & & 2.10 & & & 10.4 & 37.5 \\
\hline & TS & grass & IHF & 1963 & 1993 & cattle & & 2.10 & & & 10.3 & 38.1 \\
\hline & TS & grass & IHF & 1963 & 1993 & cattle & & 2.10 & & & 11.6 & 34.6 \\
\hline & TS & grass & IHF & 1963 & 1993 & cattle & & 2.10 & & & 10.0 & 37.4 \\
\hline & SP & grass & IHF & 1963 & 1993 & cattle & & 2.10 & & & 15.1 & 68.9 \\
\hline & SP & grass & IHF & 1963 & 1993 & cattle & & 2.10 & & & 15.8 & 66.7 \\
\hline \multirow[t]{26}{*}{ Huijsmans et al. (2003) } & SP & arable & IHF & 1521 & 1990 & pig & & 2.80 & & 6.4 & 29.2 & 37.6 \\
\hline & SP & arable & IHF & 1521 & 1990 & pig & & 5.50 & & 10.1 & 38.6 & 68.7 \\
\hline & SP & arable & IHF & 1521 & 1990 & pig & & 6.10 & & 8.6 & 21.4 & 46.9 \\
\hline & SP & arable & IHF & 1521 & 1990 & pig & & 5.50 & & 8.8 & 17.9 & 80.4 \\
\hline & SP & arable & IHF & 1521 & 1990 & pig & & 5.30 & & 8.2 & 22.0 & 95.4 \\
\hline & SP & arable & IHF & 1521 & 1990 & pig & & 4.90 & & 9.7 & 20.4 & 68.0 \\
\hline & SP & arable & IHF & 1521 & 1990 & pig & & 5.00 & & 8.7 & 22.6 & 66.3 \\
\hline & SP & arable & IHF & 1521 & 1991 & pig & & 4.10 & & 7.6 & 18.2 & 54.2 \\
\hline & SP & arable & IHF & 1521 & 1991 & pig & & 3.90 & & 7.8 & 14.4 & 56.9 \\
\hline & SP & arable & IHF & 1521 & 1991 & pig & & 4.10 & & 9.4 & 13.6 & 78.2 \\
\hline & SP & arable & IHF & 1521 & 1991 & pig & & 2.40 & & 6.0 & 18.8 & 41.1 \\
\hline & SP & arable & IHF & 1521 & 1991 & pig & & 4.50 & & 8.4 & 14.6 & 72.8 \\
\hline & SP & arable & IHF & 1521 & 1991 & pig & & 4.20 & & 7.1 & 15.9 & 66.3 \\
\hline & SP & arable & IHF & 1521 & 1992 & pig & & 4.50 & & 9.8 & 19.0 & 62.1 \\
\hline & SP & arable & IHF & 1521 & 1992 & pig & & 4.40 & & 10.7 & 29.5 & 81.4 \\
\hline & SP & arable & IHF & 1521 & 1992 & pig & & 4.00 & & 9.8 & 16.4 & 82.2 \\
\hline & SP & arable & IHF & 1521 & 1992 & pig & & 3.90 & & 6.6 & 17.4 & 75.0 \\
\hline & SP & arable & IHF & 1521 & 1992 & pig & & 4.40 & & 7.8 & 15.3 & 92.7 \\
\hline & SP & arable & IHF & 1521 & 1992 & pig & & 3.80 & & 6.1 & 29.1 & 86.2 \\
\hline & SP & arable & IHF & 1521 & 1992 & pig & & 3.90 & & 5.6 & 28.7 & 93.2 \\
\hline & SP & arable & IHF & 1521 & 1992 & pig & & 3.80 & & 5.5 & 28.9 & 100.0 \\
\hline & SP & arable & IHF & 1521 & 1993 & pig & & 4.40 & & 13.6 & 28.9 & 63.4 \\
\hline & SP & arable & IHF & 1521 & 1993 & pig & & 4.40 & & 13.6 & 27.3 & 69.7 \\
\hline & SP & arable & IHF & 1521 & 1993 & pig & & 4.60 & & 15.3 & 15.7 & 33.9 \\
\hline & SP & arable & IHF & 1521 & 1998 & pig & & 4.80 & & 7.4 & 21.5 & 58.2 \\
\hline & SP & arable & IHF & 1521 & 1998 & pig & & 4.70 & & 6.2 & 20.8 & 61.0 \\
\hline \multirow{13}{*}{$\begin{array}{l}\text { Katz (1996) } \\
\text { (excerpts published in } \\
\text { Menzi et al., 1998) }\end{array}$} & SP & grass & IHF-Zinst & 1257 & 1992 & cattle & & 0.72 & 1.70 & 4.0 & 32.6 & 33.7 \\
\hline & SP & grass & IHF-Zinst & 1257 & 1993 & cattle & & 1.13 & 2.40 & 5.4 & 33.1 & 65.0 \\
\hline & SP & grass & IHF-Zinst & 1257 & 1993 & cattle & & 1.26 & 2.40 & 4.4 & 29.4 & 58.0 \\
\hline & SP & grass & IHF-Zinst & 1257 & 1993 & cattle & & 1.25 & 2.20 & 3.9 & 31.1 & 69.0 \\
\hline & SP & grass & IHF-Zinst & 1257 & 1993 & cattle & & 1.09 & 1.90 & 3.3 & 34.1 & 55.0 \\
\hline & SP & grass & IHF-Zinst & 1257 & 1993 & cattle & & 0.83 & 1.50 & 2.8 & 32.2 & 48.0 \\
\hline & SP & grass & IHF-Zinst & 1257 & 1993 & cattle & & 0.96 & 1.70 & 3.3 & 31.8 & 60.0 \\
\hline & SP & grass & IHF-Zinst & 1257 & 1993 & cattle & & 0.93 & 1.60 & 3.0 & 30.0 & 42.0 \\
\hline & SP & grass & IHF-Zinst & 1257 & 1993 & cattle & & 0.91 & 1.70 & 3.2 & 25.8 & 44.0 \\
\hline & SP & grass & IHF-Zinst & 1257 & 1994 & cattle & & 0.93 & 1.70 & 3.3 & 33.3 & 35.0 \\
\hline & SP & grass & IHF-Zinst & 1257 & 1994 & cattle & & 0.82 & 2.00 & 4.7 & 32.8 & 27.0 \\
\hline & SP & grass & IHF-Zinst & 1257 & 1993 & cattle & & 0.85 & 1.90 & 4.0 & 32.0 & 35.0 \\
\hline & SP & grass & IHF-Zinst & 1257 & 1993 & cattle & & 1.12 & 1.90 & 3.4 & 48.8 & 51.0 \\
\hline
\end{tabular}


Table A1. Continued.

\begin{tabular}{|c|c|c|c|c|c|c|c|c|c|c|c|c|c|}
\hline Reference & Spread. & Crop & Method & $\begin{array}{l}\text { Trial Scale } \\
{\left[\text { class or } \mathrm{m}^{2} \text { ] }\right.}\end{array}$ & Trial Yr & Sl. Type & $\begin{array}{l}U \\
{\left[\mathrm{~ms}^{-1}\right]}\end{array}$ & $\begin{array}{l}\text { TAN } \\
{\left[\mathrm{g} \mathrm{kg}^{-1}\right]}\end{array}$ & $\begin{array}{l}\mathrm{TN} \\
{\left[\mathrm{g} \mathrm{kg}^{-1}\right]}\end{array}$ & $\mathrm{pH}$ & $\begin{array}{l}\mathrm{DM} \\
{[\%]}\end{array}$ & $\begin{array}{l}\text { App. Rate } \\
{\left[\mathrm{m}^{3} \mathrm{ha}^{-1}\right]}\end{array}$ & $\begin{array}{l}\mathrm{EF} \\
{[\%]}\end{array}$ \\
\hline & SP & grass & IHF-Zinst & 1257 & 1993 & cattle & & 1.10 & 1.90 & & 3.4 & 20.5 & 75.0 \\
\hline & SP & grass & IHF-Zinst & 1257 & 1993 & cattle & & 0.96 & 1.70 & & 3.3 & 32.5 & 35.0 \\
\hline & SP & grass & IHF-Zinst & 1257 & 1993 & cattle & & 0.96 & 1.70 & & 3.3 & 31.9 & 74.0 \\
\hline & SP & grass & IHF-Zinst & 1257 & 1993 & pig & & 1.23 & 1.80 & & 1.7 & 24.8 & 54.0 \\
\hline & SP & grass & IHF-Zinst & 1257 & 1993 & pig & & 1.80 & 2.80 & & 4.3 & 19.8 & 55.0 \\
\hline & SP & grass & IHF-Zinst & 1257 & 1993 & pig & & 1.65 & 2.50 & & 3.5 & 23.0 & 68.0 \\
\hline & SP & grass & IHF-Zinst & 1257 & 1993 & pig & & 2.01 & 3.30 & & 5.7 & 18.2 & 73.0 \\
\hline & SP & grass & IHF-Zinst & 1257 & 1993 & cattle & & 1.81 & 2.00 & & 1.6 & 16.4 & 38.0 \\
\hline & SP & grass & IHF-Zinst & 1257 & 1993 & cattle & & 1.04 & 1.80 & & 3.4 & 28.7 & 42.0 \\
\hline \multirow[t]{2}{*}{ Loubet et al. (2010) } & SP & arable & AGM & field scale & 1994 & cattle & & & & 7.10 & 4.7 & & 50.0 \\
\hline & SP & arable & AGM & field scale & 2008 & cattle & & & & 7.90 & 11 & & 37.5 \\
\hline \multirow[t]{32}{*}{ Pfluke et al. (2011) } & SP & grass & $\mathrm{DC}$ & small plot & 1995 & cattle & 3.7 & & & & 14.0 & 25.0 & 14.0 \\
\hline & SP & grass & DC & small plot & 1995 & cattle & 3.7 & & & & 14.0 & 50.0 & 21.3 \\
\hline & $\mathrm{TH}$ & grass & DC & small plot & 1995 & cattle & 3.7 & & & & 14.0 & 25.0 & 9.7 \\
\hline & $\mathrm{TH}$ & grass & DC & small plot & 1995 & cattle & 3.7 & & & & 14.0 & 50.0 & 11.0 \\
\hline & SP & grass & DC & small plot & 1995 & cattle & 1.2 & & & & 10.4 & 25.0 & 24.0 \\
\hline & SP & grass & DC & small plot & 1995 & cattle & 1.2 & & & & 10.4 & 50.0 & 41.0 \\
\hline & $\mathrm{TH}$ & grass & DC & small plot & 1995 & cattle & 1.2 & & & & 10.4 & 25.0 & 13.3 \\
\hline & TH & grass & DC & small plot & 1995 & cattle & 1.2 & & & & 10.4 & 50.0 & 22.7 \\
\hline & SP & grass & DC & small plot & 1995 & cattle & 2.3 & & & & 11.8 & 25.0 & 52.7 \\
\hline & SP & grass & DC & small plot & 1995 & cattle & 2.3 & & & & 11.8 & 50.0 & 58.7 \\
\hline & $\mathrm{TH}$ & grass & DC & small plot & 1995 & cattle & 2.3 & & & & 11.8 & 25.0 & 6.0 \\
\hline & TH & grass & DC & small plot & 1995 & cattle & 2.3 & & & & 11.8 & 50.0 & 11.7 \\
\hline & SP & grass & DC & small plot & 1996 & cattle & 1.0 & & & & 8.5 & 25.0 & 18.7 \\
\hline & SP & grass & DC & small plot & 1996 & cattle & 1.0 & & & & 8.5 & 50.0 & 35.0 \\
\hline & TH & grass & DC & small plot & 1996 & cattle & 1.0 & & & & 8.5 & 25.0 & 18.0 \\
\hline & $\mathrm{TH}$ & grass & DC & small plot & 1996 & cattle & 1.0 & & & & 8.5 & 50.0 & 24.7 \\
\hline & SP & grass & DC & small plot & 1996 & cattle & 1.4 & & & & 9.3 & 25.0 & 9.0 \\
\hline & SP & grass & DC & small plot & 1996 & cattle & 1.4 & & & & 9.3 & 50.0 & 34.3 \\
\hline & TH & grass & DC & small plot & 1996 & cattle & 1.4 & & & & 9.3 & 25.0 & 16.0 \\
\hline & TH & grass & DC & small plot & 1996 & cattle & 1.4 & & & & 9.3 & 50.0 & 20.0 \\
\hline & SP & grass & DC & small plot & 1996 & cattle & 1.1 & & & & 10.8 & 25.0 & 31.7 \\
\hline & SP & grass & DC & small plot & 1996 & cattle & 1.1 & & & & 10.8 & 50.0 & 30.7 \\
\hline & TH & grass & DC & small plot & 1996 & cattle & 1.1 & & & & 10.8 & 25.0 & 38.7 \\
\hline & $\mathrm{TH}$ & grass & DC & small plot & 1996 & cattle & 1.1 & & & & 10.8 & 50.0 & 21.3 \\
\hline & SP & grass & DC & small plot & 1997 & cattle & 0.8 & & & & 12.6 & 25.0 & 7.3 \\
\hline & SP & grass & DC & small plot & 1997 & cattle & 0.8 & & & & 12.6 & 50.0 & 27.8 \\
\hline & $\mathrm{TH}$ & grass & DC & small plot & 1997 & cattle & 0.8 & & & & 12.6 & 25.0 & 4.9 \\
\hline & $\mathrm{TH}$ & grass & DC & small plot & 1997 & cattle & 0.8 & & & & 12.6 & 50.0 & 10.8 \\
\hline & SP & grass & DC & small plot & 1997 & cattle & 1.4 & & & & 11.3 & 25.0 & 8.3 \\
\hline & SP & grass & DC & small plot & 1997 & cattle & 1.4 & & & & 11.3 & 50.0 & 16.3 \\
\hline & TH & grass & DC & small plot & 1997 & cattle & 1.4 & & & & 11.3 & 25.0 & 5.3 \\
\hline & $\mathrm{TH}$ & grass & $\mathrm{DC}$ & small plot & 1997 & cattle & 1.4 & & & & 11.3 & 50.0 & 9.7 \\
\hline \multirow[t]{8}{*}{ Berkhout et al. (2008) } & $\mathrm{TH}$ & arable & MBM & 452 & 2006 & pig & & 3.81 & & 7.60 & 7.6 & 49.6 & 22.5 \\
\hline & $\mathrm{TH}$ & arable & MBM & 804 & 2007 & pig & & 3.83 & & 7.80 & 5.9 & 41.8 & 50.0 \\
\hline & $\mathrm{TH}$ & arable & IHF & 804 & 2007 & pig & & 3.83 & & 7.80 & 5.9 & 41.8 & 62.0 \\
\hline & $\mathrm{TH}$ & arable & MBM & 804 & 2007 & pig & & 3.83 & & 7.80 & 5.9 & 41.8 & 42.0 \\
\hline & TH & grass & MBM & field scale & 2007 & pig & & 3.98 & & 8.00 & 5.4 & 30.9 & 39.0 \\
\hline & $\mathrm{TH}$ & grass & MBM & field scale & 2007 & pig/cattle & & 2.74 & & 7.50 & 5.9 & 33.5 & 33.0 \\
\hline & $\mathrm{TH}$ & grass & MBM & field scale & 2007 & pig/cattle & & 2.47 & & 7.50 & 6.1 & 23.3 & 38.0 \\
\hline & $\mathrm{TH}$ & grass & MBM & field scale & 2007 & pig/cattle & & 2.43 & & 7.50 & 7.2 & 22.2 & 40.0 \\
\hline Rochette et al. (2001) & SP & arable & WTu & small plot & 1999 & pig & & 2.03 & 2.52 & 8.20 & 1.6 & 74.0 & 16.9 \\
\hline Rochette et al. (2009) & SP & arable & WTu & small plot & 2006 & pig & & 2.90 & 5.20 & 7.00 & 6.7 & 29.7 & 46.5 \\
\hline Sanz et al. (2010) & SP & arable & WT & field scale & 2006 & pig & & 1.60 & 2.10 & 6.80 & 4.6 & 59.5 & 20.0 \\
\hline Sherlock et al. (2002) & SP & grass & IHF & 9 & 1995 & pig & & 4.20 & 6.10 & 8.14 & 4.4 & 60.0 & 22.5 \\
\hline
\end{tabular}


Table A1. Continued.

\begin{tabular}{|c|c|c|c|c|c|c|c|c|c|c|c|c|c|}
\hline Reference & Spread. & Crop & Method & $\begin{array}{l}\text { Trial Scale } \\
{\left[\text { class or } \mathrm{m}^{2}\right]}\end{array}$ & Trial Yr & Sl. Type & $\begin{array}{l}U \\
{\left[\mathrm{~m} \mathrm{~s}^{-1}\right]}\end{array}$ & $\begin{array}{l}\text { TAN } \\
{\left[\mathrm{g} \mathrm{kg}^{-1}\right]}\end{array}$ & $\begin{array}{l}\mathrm{TN} \\
{\left[\mathrm{g} \mathrm{kg}^{-1}\right]}\end{array}$ & $\mathrm{pH}$ & $\begin{array}{l}\mathrm{DM} \\
{[\%]}\end{array}$ & $\begin{array}{l}\text { App. Rate } \\
{\left[\mathrm{m}^{3} \mathrm{ha}^{-1}\right]}\end{array}$ & $\begin{array}{l}\mathrm{EF} \\
{[\%]}\end{array}$ \\
\hline \multirow[t]{2}{*}{ Sintermann et al. (2011a) } & SP & arable & $\mathrm{EC}$ & field scale & 2009 & cattle & 2.0 & 0.87 & 1.07 & 7.82 & 1.0 & 41.0 & 15.7 \\
\hline & SP & grass & EC & field scale & 2009 & cattle & 1.5 & 1.18 & 1.57 & 7.49 & 2.0 & 22.5 & 18.7 \\
\hline \multirow[t]{47}{*}{ Smith et al. (2000) } & SP & grass & WTu & small plot & 1995 & cattle & & 1.00 & 1.80 & 7.30 & 3.4 & 30.0 & 96.0 \\
\hline & SP & grass & WTu & small plot & 1995 & cattle & & 1.00 & 1.70 & 7.40 & 3.6 & 30.0 & 41.3 \\
\hline & SP & grass & WTu & small plot & 1995 & cattle & & 2.00 & 5.00 & 7.50 & 8.8 & 30.0 & 62.7 \\
\hline & SP & grass & WTu & small plot & 1995 & cattle & & 1.10 & 2.10 & 7.50 & 4.0 & 30.0 & 49.4 \\
\hline & SP & arable & WTu & small plot & 1995 & cattle & & 1.00 & 1.60 & 7.40 & 2.5 & 30.0 & 23.0 \\
\hline & SP & grass & WTu & small plot & 1995 & cattle & & 0.80 & 1.60 & 7.30 & 3.6 & 30.0 & 22.1 \\
\hline & $\mathrm{TH}$ & grass & WTu & small plot & 1995 & cattle & & 1.00 & 1.80 & 7.30 & 3.4 & 30.0 & 33.3 \\
\hline & $\mathrm{TH}$ & grass & WTu & small plot & 1995 & cattle & & 1.00 & 1.70 & 7.40 & 3.6 & 30.0 & 23.7 \\
\hline & $\mathrm{TH}$ & grass & WTu & small plot & 1995 & cattle & & 2.00 & 5.00 & 7.50 & 8.8 & 30.0 & 62.5 \\
\hline & TH & grass & WTu & small plot & 1995 & cattle & & 1.10 & 2.10 & 7.50 & 4.0 & 30.0 & 37.0 \\
\hline & $\mathrm{TH}$ & arable & WTu & small plot & 1995 & cattle & & 1.00 & 1.60 & 7.40 & 2.5 & 30.0 & 22.3 \\
\hline & $\mathrm{TH}$ & grass & WTu & small plot & 1995 & cattle & & 0.80 & 1.60 & 7.30 & 3.6 & 30.0 & 15.8 \\
\hline & TS & grass & WTu & small plot & 1995 & cattle & & 1.00 & 1.80 & 7.30 & 3.4 & 30.0 & 34.0 \\
\hline & TS & grass & WTu & small plot & 1995 & cattle & & 1.00 & 1.70 & 7.40 & 3.6 & 30.0 & 31.7 \\
\hline & TS & grass & WTu & small plot & 1995 & cattle & & 2.00 & 5.00 & 7.50 & 8.8 & 30.0 & 40.5 \\
\hline & $\mathrm{TS}$ & grass & WTu & small plot & 1995 & cattle & & 1.10 & 2.10 & 7.50 & 4.0 & 30.0 & 47.9 \\
\hline & $\mathrm{TS}$ & arable & WTu & small plot & 1995 & cattle & & 1.00 & 1.60 & 7.40 & 2.5 & 30.0 & 18.0 \\
\hline & TS & grass & WTu & small plot & 1995 & cattle & & 0.80 & 1.60 & 7.30 & 3.6 & 30.0 & 14.6 \\
\hline & SP & arable & WTu & small plot & 1996 & cattle & & 1.10 & 1.50 & 7.50 & 2.0 & 30.0 & 9.1 \\
\hline & SP & grass & WTu & small plot & 1996 & cattle & & 1.40 & 2.30 & 7.30 & 4.6 & 30.0 & 31.9 \\
\hline & SP & arable & WTu & small plot & 1996 & cattle & & 0.90 & 1.40 & 7.20 & 2.0 & 30.0 & 21.1 \\
\hline & SP & grass & WTu & small plot & 1996 & cattle & & 1.10 & 2.30 & 7.30 & 4.6 & 30.0 & 59.4 \\
\hline & SP & arable & WTu & small plot & 1996 & cattle & & 0.60 & 1.10 & 6.70 & 1.9 & 30.0 & 49.5 \\
\hline & SP & grass & WTu & small plot & 1996 & cattle & & 1.50 & 1.90 & & 4.6 & 30.0 & 24.9 \\
\hline & $\mathrm{TH}$ & arable & WTu & small plot & 1996 & cattle & & 1.10 & 1.50 & 7.50 & 2.0 & 30.0 & 10.3 \\
\hline & $\mathrm{TH}$ & grass & WTu & small plot & 1996 & cattle & & 1.40 & 2.30 & 7.30 & 4.6 & 30.0 & 13.1 \\
\hline & TH & arable & WTu & small plot & 1996 & cattle & & 0.90 & 1.40 & 7.20 & 2.0 & 30.0 & 16.1 \\
\hline & $\mathrm{TH}$ & grass & WTu & small plot & 1996 & cattle & & 1.10 & 2.30 & 7.30 & 4.6 & 30.0 & 38.2 \\
\hline & $\mathrm{TH}$ & arable & WTu & small plot & 1996 & cattle & & 0.60 & 1.10 & 6.70 & 1.9 & 30.0 & 22.6 \\
\hline & TH & grass & WTu & small plot & 1996 & cattle & & 1.50 & 1.90 & & 4.6 & 30.0 & 13.3 \\
\hline & TS & arable & WTu & small plot & 1996 & cattle & & 1.10 & 1.50 & 7.50 & 2.0 & 30.0 & 13.9 \\
\hline & TS & grass & WTu & small plot & 1996 & cattle & & 1.40 & 2.30 & 7.30 & 4.6 & 30.0 & 7.9 \\
\hline & TS & arable & WTu & small plot & 1996 & cattle & & 0.90 & 1.40 & 7.20 & 2.0 & 30.0 & 15.4 \\
\hline & TS & grass & WTu & small plot & 1996 & cattle & & 1.10 & 2.30 & 7.30 & 4.6 & 30.0 & 25.6 \\
\hline & TS & grass & WTu & small plot & 1996 & cattle & & 1.50 & 1.90 & & 4.6 & 30.0 & 9.6 \\
\hline & SP & arable & WTu & small plot & 1997 & cattle & & 0.80 & 1.10 & 7.20 & 2.1 & 30.0 & 16.5 \\
\hline & SP & grass & WTu & small plot & 1997 & cattle & & 1.00 & 2.40 & 6.90 & 4.8 & 30.0 & 44.0 \\
\hline & SP & arable & WTu & small plot & 1997 & cattle & & 0.40 & 1.00 & 7.60 & 2.4 & 30.0 & 31.7 \\
\hline & SP & grass & WTu & small plot & 1997 & cattle & & 1.10 & 2.30 & 7.40 & 4.4 & 30.0 & 50.0 \\
\hline & $\mathrm{TH}$ & arable & WTu & small plot & 1997 & cattle & & 0.80 & 1.10 & 7.20 & 2.1 & 30.0 & 10.4 \\
\hline & $\mathrm{TH}$ & grass & WTu & small plot & 1997 & cattle & & 1.00 & 2.40 & 6.90 & 4.8 & 30.0 & 20.0 \\
\hline & $\mathrm{TH}$ & arable & WTu & small plot & 1997 & cattle & & 0.40 & 1.00 & 7.60 & 2.4 & 30.0 & 17.5 \\
\hline & $\mathrm{TH}$ & grass & WTu & small plot & 1997 & cattle & & 1.10 & 2.30 & 7.40 & 4.4 & 30.0 & 29.7 \\
\hline & TS & arable & WTu & small plot & 1997 & cattle & & 0.80 & 1.10 & 7.20 & 2.1 & 30.0 & 13.5 \\
\hline & TS & grass & WTu & small plot & 1997 & cattle & & 1.00 & 2.40 & 6.90 & 4.8 & 30.0 & 16.0 \\
\hline & TS & arable & WTu & small plot & 1997 & cattle & & 0.40 & 1.00 & 7.60 & 2.4 & 30.0 & 45.0 \\
\hline & TS & grass & WTu & small plot & 1997 & cattle & & 1.10 & 2.30 & 7.40 & 4.4 & 30.0 & 30.3 \\
\hline \multirow[t]{3}{*}{ Smith et al. (2007) } & SP & arable & MBM & 38 & 2006 & pig & 0.9 & 2.80 & 7.00 & 6.30 & 5.5 & 33.0 & 41.1 \\
\hline & SP & arable & MBM & 38 & 2006 & pig & 0.8 & 2.80 & 7.00 & 6.30 & 5.5 & 33.0 & 44.4 \\
\hline & SP & arable & MBM & 38 & 2006 & pig & 0.8 & 2.80 & 7.00 & 6.30 & 5.5 & 33.0 & 45.5 \\
\hline \multirow[t]{9}{*}{ Smith et al. (2008) } & SP & arable & WTu & small plot & 2005 & pig & 1.0 & 2.80 & 7.00 & 6.30 & 6.0 & 36.0 & 30.0 \\
\hline & SP & arable & WTu & small plot & 2005 & pig & 1.0 & 2.80 & 7.00 & 6.30 & 6.0 & 72.0 & 27.0 \\
\hline & SP & arable & WTu & small plot & 2005 & pig & 1.0 & 2.80 & 7.00 & 6.30 & 6.0 & 180.0 & 24.0 \\
\hline & SP & arable & WTu & small plot & 2005 & pig & 1.1 & 2.80 & 7.00 & 6.30 & 6.0 & 36.0 & 26.0 \\
\hline & SP & arable & WTu & small plot & 2005 & pig & 1.1 & 2.80 & 7.00 & 6.30 & 6.0 & 72.0 & 44.0 \\
\hline & SP & arable & WTu & small plot & 2005 & pig & 1.2 & 2.80 & 7.00 & 6.30 & 6.0 & 36.0 & 20.0 \\
\hline & SP & arable & WTu & small plot & 2005 & pig & 1.2 & 2.80 & 7.00 & 6.30 & 6.0 & 72.0 & 25.0 \\
\hline & SP & arable & WTu & small plot & 2005 & pig & 1.2 & 2.80 & 7.00 & 6.30 & 6.0 & 180.0 & 21.0 \\
\hline & SP & arable & WTu & small plot & 2005 & pig & 1.2 & 2.80 & 7.00 & 6.30 & 6.0 & 36.0 & 12.0 \\
\hline
\end{tabular}


Table A1. Continued.

\begin{tabular}{|c|c|c|c|c|c|c|c|c|c|c|c|c|c|}
\hline Reference & Spread. & Crop & Method & $\begin{array}{l}\text { Trial Scale } \\
{\left[\text { class or } \mathrm{m}^{2} \text { ] }\right.}\end{array}$ & Trial Yr & S1. Type & $\begin{array}{l}U \\
{\left[\mathrm{~m} \mathrm{~s}^{-1}\right]}\end{array}$ & $\begin{array}{l}\text { TAN } \\
{\left[\mathrm{g} \mathrm{kg}^{-1}\right]}\end{array}$ & $\begin{array}{l}\mathrm{TN} \\
{\left[\mathrm{g} \mathrm{kg}^{-1}\right]}\end{array}$ & $\mathrm{pH}$ & $\begin{array}{l}\mathrm{DM} \\
{[\%]}\end{array}$ & $\begin{array}{l}\text { App. Rate } \\
{\left[\mathrm{m}^{3} \mathrm{ha}^{-1}\right]}\end{array}$ & $\begin{array}{l}\mathrm{EF} \\
{[\%]}\end{array}$ \\
\hline \multirow{23}{*}{ Sommer and Olesen (1991) } & SP & arable & WTu & small plot & 2005 & pig & 1.2 & 2.80 & 7.00 & 6.30 & 6.0 & 36.0 & 22.0 \\
\hline & SP & arable & WTu & small plot & 2005 & pig & 1.3 & 2.80 & 7.00 & 6.30 & 6.0 & 36.0 & 40.0 \\
\hline & SP & arable & WTu & small plot & 2005 & pig & 1.3 & 2.80 & 7.00 & 6.30 & 6.0 & 36.0 & 33.0 \\
\hline & SP & arable & WTu & small plot & 2005 & pig & 1.1 & 2.80 & 7.00 & 6.30 & 6.0 & 30.0 & 22.0 \\
\hline & SP & arable & WTu & small plot & 1989 & cattle & 3.4 & 1.60 & 4.90 & & 22.0 & 30.0 & 68.0 \\
\hline & SP & arable & WTu & small plot & 1989 & cattle & 3.4 & 2.50 & 2.90 & & 0.9 & 30.0 & 5.4 \\
\hline & SP & arable & WTu & small plot & 1989 & cattle & 3.6 & 2.50 & 2.90 & & 0.9 & 30.0 & 6.6 \\
\hline & SP & arable & WTu & small plot & 1989 & cattle & 3.8 & 1.60 & 4.90 & & 22.0 & 30.0 & 37.3 \\
\hline & SP & grass & WTu & small plot & 1989 & cattle & 3.2 & 1.70 & 3.10 & & 6.9 & 30.0 & 30.1 \\
\hline & SP & grass & WTu & small plot & 1989 & cattle & 2.8 & 2.20 & 3.30 & & 4.1 & 30.0 & 18.5 \\
\hline & SP & grass & WTu & small plot & 1989 & cattle & 2.8 & 2.60 & 3.70 & & 3.6 & 30.0 & 11.1 \\
\hline & SP & grass & WTu & small plot & 1989 & cattle & 3.6 & 2.70 & 3.90 & & 2.8 & 30.0 & 4.6 \\
\hline & SP & grass & WTu & small plot & 1989 & cattle & 3.7 & 2.80 & 4.20 & & 8.2 & 30.0 & 12.3 \\
\hline & SP & grass & WTu & small plot & 1989 & cattle & 3.4 & 2.90 & 4.90 & & 15.6 & 30.0 & 31.1 \\
\hline & SP & grass & WTu & small plot & 1989 & cattle & 3.6 & 2.70 & 3.90 & & 2.8 & 30.0 & 18.6 \\
\hline & SP & grass & WTu & small plot & 1989 & cattle & 3.7 & 2.80 & 4.20 & & 8.2 & 30.0 & 27.3 \\
\hline & SP & grass & WTu & small plot & 1989 & cattle & 3.4 & 2.90 & 4.90 & & 15.6 & 30.0 & 51.2 \\
\hline & SP & grass & WTu & small plot & 1989 & cattle & 3.3 & 3.00 & 4.40 & & 5.2 & 30.0 & 15.1 \\
\hline & SP & grass & WTu & small plot & 1989 & cattle & 3.1 & 2.90 & 4.30 & & 6.0 & 30.0 & 17.9 \\
\hline & SP & grass & WTu & small plot & 1989 & cattle & 3.2 & 2.90 & 4.60 & & 10.0 & 30.0 & 39.3 \\
\hline & SP & grass & WTu & small plot & 1989 & cattle & 3.3 & 3.00 & 4.40 & & 5.2 & 30.0 & 13.3 \\
\hline & SP & grass & WTu & small plot & 1989 & cattle & 3.1 & 2.90 & 4.30 & & 6.0 & 30.0 & 12.7 \\
\hline & SP & grass & WTu & small plot & 1989 & cattle & 3.2 & 2.90 & 4.60 & & 10.0 & 30.0 & 25.0 \\
\hline \multirow[t]{8}{*}{ Sommer et al. (2006) } & SP & arable & $\mathrm{DC}$ & small plot & & cattle & 0.1 & 1.70 & 3.50 & 7.50 & 7.6 & 109.0 & 10.5 \\
\hline & SP & arable & $\mathrm{DC}$ & small plot & & pig & 0.1 & 3.30 & 4.70 & 7.40 & 3.8 & 109.0 & 7.5 \\
\hline & SP & arable & $\mathrm{DC}$ & small plot & & pig & 0.1 & 4.10 & 5.60 & 8.10 & 3.4 & 109.0 & 9.5 \\
\hline & SP & arable & $\mathrm{DC}$ & small plot & & pig & 0.1 & 4.00 & 5.00 & 8.20 & 2.3 & 109.0 & 5.0 \\
\hline & SP & arable & $\mathrm{DC}$ & small plot & & cattle & 0.1 & 1.70 & 3.50 & 7.50 & 7.6 & 109.0 & 13.0 \\
\hline & SP & arable & $\mathrm{DC}$ & small plot & & pig & 0.1 & 3.30 & 4.70 & 7.40 & 3.8 & 109.0 & 12.5 \\
\hline & SP & arable & $\mathrm{DC}$ & small plot & & pig & 0.1 & 4.10 & 5.60 & 8.10 & 3.4 & 109.0 & 15.0 \\
\hline & SP & arable & $\mathrm{DC}$ & small plot & & pig & 0.1 & 4.00 & 5.00 & 8.20 & 2.3 & 109.0 & 12.0 \\
\hline \multirow[t]{6}{*}{ Spirig et al. (2010) } & SP & grass & AGM & field scale & 2006 & cattle & 1.1 & 1.05 & & & 1.1 & 45.0 & 10.5 \\
\hline & SP & grass & AGM & field scale & 2006 & cattle & 1.6 & 0.79 & & & 1.0 & 56.1 & 4.1 \\
\hline & SP & grass & AGM & field scale & 2006 & cattle & 1.7 & 1.44 & & & 3.5 & 44.7 & 8.3 \\
\hline & SP & grass & AGM & field scale & 2007 & cattle & 2.6 & 1.25 & & & 4.8 & 41.8 & 8.3 \\
\hline & SP & grass & AGM & field scale & 2007 & cattle & 1.0 & 1.04 & & & 2.5 & 46.9 & 12.2 \\
\hline & SP & grass & AGM & field scale & 2007 & cattle & 5.1 & 1.09 & & & 2.7 & 41.8 & 6.1 \\
\hline \multirow[t]{7}{*}{ Wulf et al. (2002) } & SP & grass & $\mathrm{SC}$ & 9 & 1999 & cattle & & 2.20 & 3.80 & 8.90 & 4.8 & 30.0 & 33.0 \\
\hline & $\mathrm{TH}$ & grass & $\mathrm{SC}$ & 9 & 1999 & cattle & & 2.20 & 3.80 & 8.90 & 4.8 & 30.0 & 23.0 \\
\hline & TS & grass & SC & 9 & 1999 & cattle & & 2.20 & 3.80 & 8.90 & 4.8 & 30.0 & 14.0 \\
\hline & SP & arable & $\mathrm{SC}$ & 9 & 1999 & cattle & & 2.20 & 3.80 & 8.90 & 4.8 & 30.0 & 33.0 \\
\hline & $\mathrm{TH}$ & arable & $\mathrm{SC}$ & 9 & 1999 & cattle & & 2.20 & 3.80 & 8.90 & 4.8 & 30.0 & 30.0 \\
\hline & $\mathrm{TH}$ & grass & $\mathrm{SC}$ & 9 & 1999 & cattle & & 1.60 & 4.30 & 7.60 & 8.1 & 30.0 & 47.0 \\
\hline & $\mathrm{TH}$ & arable & $\mathrm{SC}$ & 9 & 1999 & cattle & & 1.60 & 4.30 & 7.60 & 8.1 & 30.0 & 34.0 \\
\hline
\end{tabular}

$\mathrm{SC}(+\mathrm{E})=$ Static Chamber $(+\mathrm{E}), \mathrm{DC}=$ Dynamic Chamber, WTu = Wind Tunnel, MBM = Mass Balance Method, IHF = Integrated Horizontal Flux Method, WT = WindTrax, AGM $=$ Aerodynamic Gradient Method, EC = Eddy Covariance, $\mathrm{SC}=$ standard comparison, $\mathrm{SP}=$ Broadspreading $(\mathrm{Splash} \mathrm{Plate})$, TH = Trailing Hose, TS = Trailing Shoe, $\mathrm{PV}=$ Pendelverteiler

Acknowledgements. For funding our work we gratefully thank the Swiss National Science Foundation (TERMS, 200021-117686/1) and the EU project NitroEurope (Contract 017841) that is funded under the EC 6th Framework Programme for Research and Technological Development.

Edited by: E. Nemitz

\section{References}

Ammann, C., Brunner, A., Spirig, C., and Neftel, A.: Technical note: Water vapour concentration and flux measurements with PTR-MS, Atmos. Chem. Phys., 6, 4643-4651, doi:10.5194/acp6-4643-2006, 2006.
Amon, B., Kryvoruchko, V., Amon, T., and ZechmeisterBoltenstern, S.: Methane, nitrous oxide and ammonia emissions during storage and after application of dairy cattle slurry and influence of slurry treatment, Agr. Ecosyst. Environ., 112, 153162, doi:10.1016/j.agee.2005.08.030, 2006.

Baldocchi, D. D., Hicks, B. B., and Meyers, T. P.: Measuring biosphere-atmosphere exchanges of biologically related gases with micrometeorological methods, Ecology, 69, 1331-1340, 1988.

Balsari, P., Dinuccio, E., Santoro, E., and Gioelli, F.: Ammonia emissions from rough cattle slurry and from derived solid and liquid fractions applied to alfalfa pasture, Aust. J. Exp. Agr., 48, 198-201, doi:10.1071/EA07234, 2008. 
Berkhout, A. J. C., van der Hoff, G. R., Bergwerff, J. B., Swart, D. J. P., Hensen, A., Kraai, A., Bleeker, A., Huijsmans, J. F. M., Mosquera, J., and van Pul, W. A. J.: Measuring ammonia emissions from manured fields, no. 680150003 in RIVM Report, National Institute for Public Health and the Environment, Bilthoven, The Netherlands, 2008.

Bleeker, A., Sutton, M. A., Acherman, B., Alebic-Juretic, A., Aneja, V. P., Ellermann, T., Erisman, J. W., Fowler, D., Fagerli, H., Gauger, T., Harlen, K. S., Hole, L. R., Horvath, L., Mitosinkova, M., Smith, R. I., Tang, Y. S., and van Pul, A.: Linking ammonia emission trends to measured concentrations and deposition of reduced nitrogen at different scales, in: Atmospheric Ammonia - detecting emission changes and environmental impacts, edited by: Sutton, M. A., Reis, S., and Baker, S. M. H., 123-180, Springer, 2009.

Bhandral, R., Bittman, S., Kowalenko, G., Buckley, K., Chantigny, M. H., Hunt, D. E., Bounaix, F., and Friesen, A.: Enhancing Soil Infiltration Reduces Gaseous Emissions and Improves N Uptake from Applied Dairy Slurry, J. Environ. Qual., 38, 1372-1382, doi:10.2134/jeq2008.0287, 2009.

Beuning, J. D., Pattey, E., Edwards, G., and van Heyst, B. J.: Improved temporal resolution in process-based modelling of agricultural soil ammonia emissions, Atmos. Environ., 42, 3253$3265,2008$.

Bittman, S., van Vliet, L. J. P., Kowalenko, C. G., McGinn, S., Hunt, D. E., and Bounaix, F.: Surface-banding liquid manure over aeration slots: A new low-disturbance method for reducing ammonia emissions and improving yield of perennial grasses, Agron. J., 97, 1304-1313, 2005.

Brodeur, J. J., Warland, J. S., Staebler, R. M., and Wagner-Riddle, C.: Technical note: Laboratory evaluation of a tunable diode laser system for eddy covariance measurements of ammonia flux, Agr. Forest Meteorol., 149, 385-391, 2009.

Chantigny, M. H., Rochette, P., Angers, D. A., Masse, D., and Cote, D.: Ammonia volatilization and selected soil characteristics following application of anaerobically digested pig slurry, Soil Sci. Soc. Am. J., 68, 306-312, 2004.

Chantigny, M. H., MacDonald, J. D., Beaupre, C., Rochette, P., Angers, D. A., Masse, D., and Parent, L.: Ammonia volatilization following surface application of raw and treated liquid swine manure, Nutr. Cycl. Agroecosys., 85, 275-286, doi:10.1007/s10705-009-9266-7, 2009.

Dabberdt, W. F., Lenschow, D. H., Horst, T. W., Zimmermann, P. R., Oncley, S. P., and Delany, A. C.: Atmosphere-surface exchange measurements, Science, 260, 1472-1481, 1993.

de Vries, H. S. M., Harren, F. J. M., Wyers, G. P., Otjes, R. P., Slanina, J., and Reuss, J.: Non-intrusive, fast and sensitive ammonia detection by laser photothermal deflection, Atmos. Environ., 29, 1069-1074, 1995.

Denmead, O. T.: Micrometeorological methods for measuring gaseous losses of nitrogen in the field, in: Gaseous Loss of Nitrogen from Plant-Soil Systems, Kluwer Academic Publisher, Dordrecht, 133-157, 1983.

Denmead, O. T.: Novel meteorological methods for measuring trace gas fluxes, Philos. T. Roy. Soc. A, 351, 383-396, 1995.

Denmead, O. T.: Approaches to measuring fluxes of methane and nitrous oxide between landscapes and the atmosphere, Plant Soil, 309, 5-24, doi:10.1007/s11104-008-9599-z, 2008.
Denmead, O. T. and Raupach, M. R.: Methods for measuring atmospheric gas-transport in agricultural and forest systems, in: Agricultural Ecosystem Effects on Trace Gases and Global Climate Change, edited by Harper, L. A., Mosier, A. R., Duxbury, J. M., Rolston, D. E., Peterson, G. A., Baenziger, P. S., Luxmoore, R. J., and Kral, D. M., vol. 55 of ASA Special Publication, 19-43, Amer. Soc. Agronomy, 1993.

Denmead, O. T., Simpson, J. R., and Freney, J. R.: Direct field measurement of ammonia emission after injection of anhydrous ammonia, Soil Sci. Soc. Am. J., 41, 1001-1004, 1977.

Döhler, H., Eurich-Menden, B., Dämmgen, U., Osterburg, B., Lüttich, M., Bergschmidt, A., Berg, W., and Brunsch, R.: Adaptation of the German emission calculation methodology to international guidelines, determination and forecasting of ammonia emissions from German agriculture, and scenarios for reducing them by 2010, Forschungsbericht UBA-FB 000249, Umweltbundesamt, Berlin, 2002.

ECETOC: Ammonia emissions to air in Western Europe, Technical Report 62, European Centre for Ecotoxicology and Toxicology of Chemicals, Brussels, Belgium, 1994.

EEA: EMEP/EEA emission inventory guidebook 2009, European Environment Agency, Office for Official Publications of the European Communities, Luxembourg, http://www.eea.europa eu/publications/emep-eea-emission-inventory-guidebook-2009, 2009.

Ellis, R. A., Murphy, J. G., Pattey, E., van Haarlem, R., O’Brien, J. M., and Herndon, S. C.: Characterizing a Quantum Cascade Tunable Infrared Laser Differential Absorption Spectrometer (QCTILDAS) for measurements of atmospheric ammonia, Atmos. Meas. Tech., 3, 397-406, doi:10.5194/amt-3-397-2010, 2010.

Erisman, J. W., Bleeker, A., Galloway, J., and Sutton, M. S.: Reduced nitrogen in ecology and the environment, Environ. Pollut., 150, 140-149, doi:10.1016/j.envpol.2007.06.033, 2007.

Erisman, J. W., Bleeker, A., Hensen, A., and Vermeulen, A.: Agricultural air quality in Europe and the future perspectives, Atmos. Environ., 42, 3209-3217, doi:10.1016/j.atmosenv.2007.04.004, 2008.

Flechard, C. R., Neftel, A., Jocher, M., Ammann, C., and Fuhrer, J.: Bi-directional soil/atmosphere $\mathrm{N}_{2} \mathrm{O}$ exchange over two mown grassland systems with contrasting management practices, Global Change Biol., 11, 2114-2127, doi:10.1111/j.13652486.2005.01056.x, 2005.

Flechard, C. R., Spirig, C., Neftel, A., and Ammann, C.: The annual ammonia budget of fertilised cut grassland - Part 2: Seasonal variations and compensation point modeling, Biogeosciences, 7 , 537-556, doi:10.5194/bg-7-537-2010, 2010.

Flesch, T. K., Wilson, J. D., and Yee, E.: Backward-time lagrangian stochastic dispersion models and their application to estimate gaseous emissions, J. Appl. Meteorol., 34, 1320-1332, 1995.

Flesch, T. K., Wilson, J. D., Harper, L. A., Crenna, B. P., and Sharpe, R. R.: Deducing ground-to-air emissions from observed trace gas concentrations: A field trial, J. Appl. Meteorol., 43, 487-502, 2004.

Flesch, T. K., Wilson, J. D., Harper, L. A., and Crenna, B. P.: Estimating gas emissions from a farm with an inverse-dispersion technique, Atmos. Environ., 39, 4863-4874, doi:10.1016/j.atmosenv.2005.04.032, 2005.

Galloway, J. N., Aber, J. D., Erisman, J. W., Seitzinger, S. P., Howarth, R. W., Cowling, E. B., and Cosby, B. J.: The nitro- 
gen cascade, BioScience, 53, 341-356, 2003.

Gao, Z., Desjardins, R. L., and Flesch, T. K.: Comparison of a simplified micrometeorological mass difference technique and an inverse dispersion technique for estimating methane emissions from small area sources, Agr. Forest Meteorol., 149, 891-898, doi:10.1016/j.agrformet.2008.11.005, 2009.

Gao, Z., Desjardins, R. L., and Flesch, T. K.: Assessment of the uncertainty of using an inverse-dispersion technique to measure methane emissions from animals in a barn and in a small pen, Atmos. Environ., 44, 3128-3134, doi:10.1016/j.atmosenv.2010.05.032, 2010.

Gärtner, A., Hirschberger, R., and Kotzian, F.: Estimation of diffuse ammonia emissions during and after slurry spreading, Gefahrst. Reinhalt. L., 68, 149-155, 2008.

Génermont, S. and Cellier, P.: A mechanistic model for estimating ammonia volatilization from slurry applied to bare soil, Agr. Forest Meteorol., 88, 145-167, 1997.

Godson, W. L.: The diffusion of particulate matter from an elevated source, Arch. F. Met. Geophys. und Biokl., A(10), 305$327,1958$.

Hansen, M. N., Sommer, S. G., and Madsen, N. P.: Reduction of ammonia emission by shallow slurry injection: Injection efficiency and additional energy demand, J. Environ. Qual., 32, 1099-1104, 2003.

Herrmann, B., Jones, S. K., Fuhrer, J., Feller, U., and Neftel, A.: N budget and $\mathrm{NH}_{3}$ exchange of a grass/clover crop at two levels of $\mathrm{N}$ application, Plant Soil, 235, 243-252, 2001.

Hertel, O., Reis, S., Skjøth, C. A., Bleeker, A., Harrison, R., Cape, J. N., Fowler, D., Skiba, U., Simpson, D., Jickells, T., Baker, A., Kulmala, M., Gyldenkaerne, S., Sørensen, L. L., and Erisman, J. W.: Nitrogen processes in the atmosphere, in: The European Nitrogen Assessment - Sources, Effects and Policy Perspectives, edited by Sutton, M. A., Howard, C. M., Erisman, J. W., Billen, G., Grennfelt, P., van Grinsven, H., and Grizzetti, B., 177-207, Cambridge University Press, Cambridge, UK, 2011.

Huijsmans, J. F. M., Hol, J. M. G., and Hendriks, M. M. W.: Effect of application technique, manure characteristics, weather and field conditions on ammonia volatilization from manure applied to grassland, Neth. J. Agr. Sci., 49, 323-342, 2001.

Huijsmans, J. F. M., Hol, J. M. G., and Vermeulen, G. D.: Effect of application method, manure characteristics, weather and field conditions on ammonia volatilization from manure applied to arable land, Atmos. Environ., 37, 3669-3680, doi:10.1016/S1352-2310(03)00450-3, 2003.

Hutchings, N. J., Sommer, S. G., and Jarvis, S. C.: A model of ammonia volatilization from a grazing livestock farm, Atmos. Environ., 30, 589-599, 1996.

Jarvis, S., Hutchings, N., Brentrup, F., Olesen, J. E., and van der Hoek, K.: Nitrogen flows in farming systems across Europe, in: The European Nitrogen Assessment - Sources, Effects and Policy Perspectives, edited by Sutton, M. A., Howard, C. M., Erisman, J. W., Bleeker, A., Grennfelt, P., van Grinsven, H., and Grizzetti, B., 211-228, Cambridge University Press, Cambridge, UK, 2011.

Katz, P. E.: Ammoniakemissionen nach der Gülleanwendung auf Grünland, PhD thesis, ETH Zürich, Zürich, 1996.

Kristensen, L., Hansen, O. F., and Hojstrup, J.: Sampling bias on cup anemometer mean winds, Wind Energy, 6, 321-331, doi:10.1002/we.85, 2003.
Kroon, P. S., Hensen, A., van den Bulk, W. C. M., Jongejan, P. A. C., and Vermeulen, A. T.: The importance of reducing the systematic error due to non-linearity in $\mathrm{N}_{2} \mathrm{O}$ flux measurements by static chambers, Nutr. Cycl. Agroecosys., 82, 175-186, doi:10.1007/s10705-008-9179-x, 2008.

Laubach, J.: Testing of a Lagrangian model of dispersion in the surface layer with cattle methane emissions, Agr. Forest Meteorol. 150, 1428-1442, doi:10.1016/j.agrformet.2010.07.006, 2010.

Leip, A., Achermann, B., Billen, G., Bleeker, A., Bouwman, A. F., de Vries, W., Dragosits, U., Döring, U., Fernall, D., Geupel, M., Herolstab, J., Johnes, P., Gall, A. L., Monni, S., Neveceral, R., Orlandini, L., Prud'homme, M., Reuter, H. I., Simpson, D., Seufert, G., Spranger, T., Sutton, M. A., van Aardenne, J., Voss, M., and Winiwarter, W.: Integrating nitrogen fluxes at the European scale, in: The European Nitrogen Assessment - Sources, Effects and Policy Perspectives, edited by Sutton, M. A., Howard, C. M., Erisman, J. W., Billen, G., Bleeker, A., Grennfelt, P., van Grinsven, H., and Grizzetti, B., 345-376, Cambridge University Press, Cambridge, UK, 2011.

Leuning, R., Freney, J. R., Denmead, O. T., and Simpson, J. R.: A sampler for measuring atmospheric ammonia flux, Atmos. Environ., 19, 1117-1124, 1985.

Lim, Y., Moon, Y.-S., and Kim, T.-W.: Artificial neural network approach for prediction of ammonia emission from field-applied manure and relative significance assessment of ammonia emission factors, Europ. J. Agronomy, 26, 425-434, 2007.

Lockyer, D. R.: A system for the measurement in the field of losses of ammonia through volatilization, J. Sci. Food Agr., 35, 837848, 1984.

Loubet, B., Cellier, P., Flura, D., and Genermont, S.: An evaluation of the wind-tunnel technique for estimating ammonia volatilization from land: Part 1. Analysis and improvement of accuracy, J. Agr. Eng. Res., 72, 71-81, 1999a.

Loubet, B., Cellier, P., Genermont, S., and Flura, D.: An evaluation of the wind-tunnel technique for estimating ammonia volatilization from land: Part 2. Influence of the tunnel on transfer processes, J. Agr. Eng. Res., 72, 83-92, 1999b.

Loubet, B., Milford, C., Sutton, M. A., and Cellier, P.: Investigation of the interaction between sources and sinks of atmospheric ammonia in an upland landscape using a simplified dispersionexchange model, J. Geophys. Res.-Atmos., 106, 24183-24195, 2001.

Loubet, B., Milford, C., Hensen, A., Daemmgen, U., Erisman, J.W., Cellier, P., and Sutton, M. A.: Advection of $\mathrm{NH}_{3}$ over a pasture field and its effect on gradient flux measurements, Biogeosciences, 6, 1295-1309, doi:10.5194/bg-6-1295-2009, 2009.

Loubet, B., Génermont, S., Ferrara, R., Bedos, G., Decuq, G., Personne, E., Fanucci, O., Durand, B., Rana, G., and Cellier, P.: An inverse model to estimate ammonia emissions from fields, Eur. J. Soil Sci., 61, 793-805, doi:10.1111/j.1365-2389.2010.01268.x, 2010.

McBain, M. C. and Desjardins, R. L.: The evaluation of a backward Lagrangian stochastic (bLS) model to estimate greenhouse gas emissions from agricultural sources using a synthetic tracer source, Agr. Forest Meteorol., 135, 61-72, doi:10.1016/j.agrformet.2005.10.003, 2005.

Menzi, H., Katz, P. E., Fahrni, M., Neftel, A., and Frick, R.: A simple empirical model based on regression analysis to estimate ammonia emissions after manure application, Atmos. Environ., 
32, 301-307, 1998.

Milford, C., Theobald, M. R., Nemitz, E., Hargreaves, K. J., Horvath, L., Raso, J., Dämmgen, U., Neftel, A., Jones, S. K., Hensen, A., Loubet, B., Cellier, P., and Sutton, M. A.: Ammonia fluxes in relation to cutting and fertilization of an intensively managed grassland derived from an inter-comparison of gradient measurements, Biogeosciences, 6, 819-834, doi:10.5194/bg-6819-2009, 2009.

Misselbrook, T. H., Smith, K. A., Jackson, D. R., and Gilhespy, S. L.: Ammonia emissions from irrigation of dilute pig slurries, Biosyst. Eng., 89, 473-484, doi:10.1016/j.biosystemseng.2004.08.015, 2004.

Misselbrook, T. H., Nicholson, F. A., Chambers, B. J., and Johnson, R. A.: Measuring ammonia emissions from land applied manure: an intercomparison of commonly used samplers and techniques, Environ. Pollut., 135, 389-397, doi:10.1016/j.envpol.2004.11.012, 2005.

Misselbrook, T. H., Chadwick, D. R., Chambers, B. J., Smith, K. A., Webb, J., Demmers, T., and Sneath, R. W.: Inventory of ammonia emissions from UK agriculture 2004, Inventory Submission Report DEFRA Contract AM0127, 2006.

Neftel, A., Blatter, A., Gut, A., Hogger, D., Meixner, F., Ammann, C., and Nathaus, F. J.: $\mathrm{NH}_{3}$ soil and soil surface gas measurements in a triticale wheat field, Atmos. Environ., 32, 499-505, 1998.

Neftel, A., Spirig, C., and Ammann, C.: Application and test of a simple tool for operational footprint evaluations, Environ. Pollut., 152, 644-652, doi:10.1016/j.envpol.2007.06.062, 2008.

Norman, M., Spirig, C., Wolff, V., Trebs, I., Flechard, C., Wisthaler, A., Schnitzhofer, R., Hansel, A., and Neftel, A.: Intercomparison of ammonia measurement techniques at an intensively managed grassland site (Oensingen, Switzerland), Atmos. Chem. Phys., 9, 2635-2645, doi:10.5194/acp-9-2635-2009, 2009.

Pfluke, P. D., Jokela, W. E., and Bosworth, S. C.: Ammonia Volatilization from Surface-Banded and Broadcast Application of Liquid Dairy Manure on Grass Forage, J. Environ. Qual., 40, 374-382, doi:10.2134/jeq2010.0102, 2011.

Pogany, A., Mohacsi, A., Jones, S. K., Nemitz, E., Varga, A., Bozoki, Z., Galbacs, Z., Weidinger, T., Horvath, L., and Szabo, G.: Evaluation of a diode laser based photoacoustic instrument combined with preconcentration sampling for measuring surface-atmosphere exchange of ammonia with the aerodynamic gradient method, Atmos. Environ., 44, 1490-1496, doi:10.1016/j.atmosenv.2010.01.038, 2010.

Raupach, M. R. and Legg, B. J.: The use and limitation of fluxgradient relationships in micrometeorology, Agric. Water Manage., 8, 119-131, 1984.

Reidy, B., Dämmgen, U., Döhler, H., Eurich-Menden, B., van Evert, F. K., Hutchings, N. J., Luesink, H. H., Menzi, H., Misselbrook, T. H., Monteny, G. J., and Webb, J.: Comparison of models used for national agricultural ammonia emission inventories in Europe: Liquid manure systems, Atmos. Environ., 42, 34523464, doi:10.1016/j.atmosenv.2007.04.009, $2008 \mathrm{a}$.

Reidy, B., Rhim, B., and Menzi, H.: A new Swiss inventory of ammonia emissions from agriculture based on a survey on farm and manure management and farmspecific model calculations, Atmos. Environ., 42, 3266-3276, doi:10.1016/j.atmosenv.2007.04.036, 2008b.
Rochette, P., Chantigny, M. H., Angers, D. A., Bertrand, N., and Cote, D.: Ammonia volatilization and soil nitrogen dynamics following fall application of pig slurry on canola crop residues, Can. J. Soil Sci., 81, 515-523, 2001.

Rochette, P., Angers, D. A., Chantigny, M. H., MacDonald, J. D., Gasser, M., and Bertrand, N.: Reducing ammonia volatilization in a no-till soil by incorporating urea and pig slurry in shallow bands, Nutr. Cycl. Agroecosys., 84, 71-80, doi:10.1007/s10705008-9227-6, 2009.

Rotach, M. W.: Turbulence within and above an urban canopy, no. 45 in Zürcher Geographische Schriften, Geographisches Institut ETH Zürich, Zürich, 1991.

Sanz, A., Misselbrook, T., Sanz, M. J., and Vallejo, A.: Use of an inverse dispersion technique for estimating ammonia emission from surface-applied slurry, Atmos. Environ., 44, 999-1002, doi:10.1016/j.atmosenv.2009.08.044, 2010.

Schjoerring, J. K., Sommer, S. G., and Ferm, M.: A simple passive sampler for measuring ammonia emission in the field, Water Air Soil Poll., 62, 13-24, 1992.

Schmid, H. P.: Footprint modeling for vegetation atmosphere exchange studies: a review and perspective, Agr. Forest Meteorol., 113, 159-183, 2002.

Shaw, W. J., Spicer, C. W., and Kenny, D. V.: Eddy correlation fluxes of trace gases using a tandem mass spectrometer, Atmos. Environ., 32, 2887-2898, 1998.

Sherlock, R. R., Sommer, S. G., Khan, R. Z., Wood, C. W., Guertal, E. A., Freney, J. R., Dawson, C. O., and Cameron, K. C.: Ammonia, methane, and nitrous oxide emission from pig slurry applied to a pasture in New Zealand, J. Environ. Qual., 31, 1491-1501, 2002.

Sintermann, J., Ammann, C., Kuhn, U., Spirig, C., Hirschberger, R., Gärtner, A., and Neftel, A.: Determination of field scale ammonia emissions for common slurry spreading practice with two independent methods, Atmos. Meas. Tech., 4, 1821-1840, doi:10.5194/amt-4-1821-2011, 2011a.

Sintermann, J., Spirig, C., Jordan, A., Kuhn, U., Ammann, C., and Neftel, A.: Eddy covariance flux measurements of ammonia by high temperature chemical ionisation mass spectrometry, Atmos. Meas. Tech., 4, 599-616, doi:10.5194/amt-4-599-2011, 2011 b.

Smith, K. A., Jackson, D. R., Misselbrook, T. H., Pain, B. F., and Johnson, R. A.: Reduction of ammonia emission by slurry application techniques, J. Agr. Eng. Res., 77, 277-287, 2000.

Smith, E., Gordon, R., Bourque, C., and Campbell, A.: Comparison of three simple field methods for ammonia volatilization from manure, Can. J. Soil Sci., 87, 469-477, 2007.

Smith, E., Gordon, R., Bourque, C., and Campbell, A.: Management strategies to simultaneously reduce ammonia, nitrous oxide and odour emissions from surface-applied swine manure, Can. J. Soil Sci., 88, 571-584, 2008.

Søgaard, H. T., Sommer, S. G., Hutchings, N. J., Huijsmans, J. F. M., Bussink, D. W., and Nicholson, F.: Ammonia volatilization from field-applied animal slurry - the ALFAM model, Atmos. Environ., 36, 3309-3319, 2002.

Sommer, S. G. and Olesen, J. E.: Effects of dry-matter content and temperature on ammonia loss from surface-applied cattle slurry, J. Environ. Qual., 20, 679-683, 1991.

Sommer, S. G. and Olesen, J. E.: Modelling ammonia volatilization from animal slurry applied with trail hoses to cereals, Atmos. Environ., 34, 2361-2372, 2000. 
Sommer, S. G., Olesen, J. E., and Christensen, B. T.: Effects of temperature, wind speed and air humidity on ammonia volatilization from surface applied cattle slurry, J. Agr. Sci., 117, 91-100, 1991.

Sommer, S. G., Génermont, S., Cellier, P., Hutchings, N. J., Olesen, J. E., and Morvan, T.: Processes controlling ammonia emission from livestock slurry in the field, Eur. J. Agron., 19, 465-486, doi:10.1016/S1161-0301(03)00037-6, 2003.

Sommer, S. G., Jensen, L. S., Clausen, S. B., and Søgaard, H. T.: Ammonia volatilization from surface-applied livestock slurry as affected by slurry composition and slurry infiltration depth, J. Agr. Sci., 144, 229-235, doi:10.1017/S0021859606006022, 2006.

Spirig, C., Flechard, C. R., Ammann, C., and Neftel, A.: The annual ammonia budget of fertilised cut grassland - Part 1: Micrometeorological flux measurements and emissions after slurry application, Biogeosciences, 7, 521-536, doi:10.5194/bg-7-521-2010, 2010.

Sutton, M. A., Fowler, D., and Moncrieff, J. B.: The exchange of atmospheric ammonia with vegetated surfaces. 1 . Unfertilized vegetation, Q. J. Roy. Meteor. Soc., 119, 1023-1045, 1993.

Thomas, R. M., Trebs, I., Otjes, R., Jongejan, P. A. C., Brink, H. T., Phillips, G., Kortner, M., Meixner, F. X., and Nemitz, E.: An automated analyzer to measure surface-atmosphere exchange fluxes of water soluble inorganic aerosol compounds and reactive trace Gases, Environ. Sci. Technol., 43, 1412-1418, doi:10.1021/es8019403, 2009.

Thöni, L., Brang, P., Braun, S., Seitler, E., and Rihm, B.: Ammonia monitoring in Switzerland with passive samplers: Patterns, determinants and comparison with modelled concentrations, Environ. Monit. Assess., 98, 93-107, 2004.

Thorman, R. E., Hansen, M. N., Misselbrook, T. H., and Sommer, S. G.: Algorithm for estimating the crop height effect on ammonia emission from slurry applied to cereal fields and grassland, Agron. Sustain. Dev., 28, 373-378, doi:10.1051/agro:2008013, 2008.

Tuzson, B., Hiller, R. V., Zeyer, K., Eugster, W., Neftel, A., Ammann, C., and Emmenegger, L.: Field intercomparison of two optical analyzers for $\mathrm{CH}_{4}$ eddy covariance flux measurements, Atmos. Meas. Tech., 3, 1519-1531, doi:10.5194/amt-3-15192010, 2010.

Valli, L., Fabbri, C., and Bonazzi, G.: A national inventory of ammonia and greenhouse gas emissions from agriculture in Italy, in: Proceedings of the 9th Int. Conference on the FAO ESCORENA Network on recycling of agricultural, municipal and industrial residues in agriculture, 153-159, Gargano, Italy, 2001.

von Bobrutzki, K., Braban, C. F., Famulari, D., Jones, S. K., Blackall, T., Smith, T. E. L., Blom, M., Coe, H., Gallagher, M., Ghalaieny, M., McGillen, M. R., Percival, C. J., Whitehead, J. D., Ellis, R., Murphy, J., Mohacsi, A., Pogany, A., Junninen, H., Rantanen, S., Sutton, M. A., and Nemitz, E.: Field inter-comparison of eleven atmospheric ammonia measurement techniques, Atmos. Meas. Tech., 3, 91-112, doi:10.5194/amt-3-91-2010, 2010. van der Molen, J., Beljaars, A. C. M., Chardon, W. J., Jury, W. A., and van Faasen, H. G.: Ammonia volatilization from arable land after application of cattle slurry. 2. Derivation of a transfer model, Neth. J. Agric. Sc., 38, 239-254, 1990.

van Pul, W. A. J., van den Broek, M. M. P., Volten, V., van der Meulen, A., Berkhout, A. J. C., van der Hoek K. W., WichinkKruit, J. J., Huijsmans, J. F. M., van Jaarsveld, J. A., de Haan, B. J., and Koelemeijer, R. B. A.: Het ammoniakgat: onderzoek en duiding (The ammonia gap: research and interpretation), RIVM report 680150002/2008, 95 pp., Bilthoven, 2008.

Webb, J., Pain, B., Bittman, S., and Morgan, J.: The impacts of manure application methods on emissions of ammonia, nitrous oxide and on crop response-A review, Agr. Ecosyst. Environ., 137, 39-46, doi:10.1016/j.agee.2010.01.001, 2010.

Whitehead, J. D., Twigg, M., Famulari, D., Nemitz, E., Sutton, M. A., Gallagher, M. W., and Fowler, D.: Evaluation of laser absorption spectroscopic techniques for eddy covariance flux measurements of ammonia, Environ. Sci. Technol., 42, 2041-2046, doi:10.1021/es071596u, 2008.

Wichink-Kruit, R. J., Pul, W. A. J. V., Otjes, R. P., Hofschreuder, P., Jacobs, A. F. G., and Holtslag, A. A. M.: Ammonia fluxes and derived canopy compensation points over non-fertilized agricultural grassland in The Netherlands using the new gradient ammonia - high accuracy - monitor (GRAHAM), Atmos. Environ., 41, 1275-1287, doi:10.1016/j.atmosenv.2006.09.039, 2007.

Wilson, J. D. and Shum, W. K. N.: A re-examination of the integrated horizontal flux method for estimating volatilization from circular plots, Agr. Forest Meteorol., 57, 281-295, 1992.

Wilson, J. D., Thurtell, G. W., Kidd, G. E., and Beauchamp, E. G.: Estimation of the rate of gaseous mass-transfer from a surface source plot to the atmosphere, Atmos. Environ., 16, 1861-1867, 1982.

Wilson, J. D., Catchpoole, V. R., Denmead, O. T., and Thurtell, G. W.: Verification of a simple micrometeorological method for estimating the rate of gaseous mass-transfer from the ground to the atmosphere, Agr. Forest Meteorol., 29, 183-189, 1983.

Wulf, S., Maeting, M., and Clemens, J.: Application technique and slurry co-fermentation effects on ammonia, nitrous oxide, and methane emissions after spreading: I. Ammonia volatilization, J. Environ. Qual., 31, 1789-1794, 2002. 